\title{
ESTUDIO CUANTITATIVO DE LA INDEMNIZACIÓN DE PERJUICIOS EXTRAPATRIMONIALES POR INFRACCIONES A LOS DERECHOS DE LOS CONSUMIDORES
}

\author{
QUANTITATIVE STUDY OF THE COMPENSATION OF NON- \\ PECUNIARY DAMAGES FOR INFRINGEMENTS OF CONSUMER \\ RIGHTS
}

MAGDALENA LAZCANO MATURANA* JAVIERA TORO CÁCERES**

\section{RESUMEN}

El presente trabajo consiste en un análisis jurisprudencial de la calificación y cuantificación del daño extrapatrimonial en las sentencias que resuelven causas por infracción a la Ley $\mathrm{N}^{\circ} 19.496$ sobre protección de los derechos de los consumidores, seguidas ante Juzgados de Policía Local (JPL), que quedaron ejecutoriadas el año 2017. Su principal objetivo es identificar aquellas sentencias que acogen la demanda civil de indemnización del daño extrapatrimonial y analizar: (i) el tipo de infracciones al derecho del consumo que dan lugar a la indemnización del daño moral, (ii) los elementos que configuran el daño moral concedido y (iii) los montos de indemnización otorgados, según cada tipo de infracción.

\footnotetext{
*Abogada. Licenciada en Cs. Jurídicas, Universidad de Chile. Correo electrónico: maida.lazcano@ gmail.com.

**Abogada. Licenciada en Cs. Jurídicas, Universidad de Chile. Estudiante de Magíster en Derecho, con mención en Derecho Público, Universidad de Chile. Correo electrónico: javieratorocaceres@gmail.com. Agradecemos a Nina Romero y Joaquín Carbone, cuyo apoyo en la recopilación de los fallos estudiados en este trabajo fue fundamental para la elaboración del análisis que se expone.

Artículo recibido a evaluación el 21 de noviembre de 2018, y aceptado para su publicación el 31 de mayo de 2019.
} 
Palabras clave: Daño moral - Indemnización - Derecho del consumidorJurisprudencia.

\section{ABSTRACT}

This paper consists in a jurisprudential analysis of the qualification and quantification of non-pecuniary damages in the judgments handed down during the year 2017 in cases for infringement of Chilean consumer's rights protection Act (Law No. 19.496). Its main objective is to identify those judgments that accept the civil claim for compensation of nonpecuniary damage and analyze: (i) the type of infractions that give rise to compensation for non-pecuniary damage, (ii) the elements that configures the non-pecuniary damage granted and (iii) the amounts of compensation awarded, according to each type of infraction.

Keywords: Non-pecuniary damages - Compensation - Consumer Law Jurisprudence.

\section{INTRODUCCIÓN. EL DAÑO MORAL COMO MECANISMO DE PROTECCIÓN DE LOS DERECHOS DE LOS CONSUMIDORES}

El objeto de este trabajo es estudiar las decisiones de los Tribunales de Justicia chilenos respecto a la indemnización del daño moral causado por infracciones a los derechos de los consumidores. La relevancia de este estudio, desde la perspectiva del derecho del consumo nacional, está dada por el lugar preponderante que ocupa la responsabilidad civil como mecanismo de cumplimiento o enforcement de éste. ${ }^{1}$ Lo anterior es consecuencia, tanto de

\footnotetext{
1 Se ha señalado que existirían seis mecanismos posibles para lograr el cumplimiento del derecho del consumo: la litigación civil individual, los mecanismos de resolución alternativa de conflictos, el enforcement administrativo, las sanciones criminales, las acciones grupales o colectivas y la autorregulación (ANDRADE RAMírez, Víctor, "Derecho del consumo. Un breve relato sobre sus fundamentos teóricos, desarrollos y nuevas tendencias", Memoria para optar al grado de licenciado en ciencias jurídicas y sociales, Universidad de Chile, Santiago, 2015, no publicada, p. 117). Sin embargo, en Chile no existe enforcement administrativo en esta materia -la reforma reciente que buscó establecerlo fue declarada inconstitucional-y los mecanismos de resolución alternativa de conflictos, las sanciones criminales y la autorregulación cumplen un rol acotado. Por lo tanto, los principales mecanismos disponibles para los consumidores frente a los incumplimientos de un proveedor es la litigación -ya sea individual o colectiva- para obtener la imposición de multas, la nulidad de cláusulas abusivas y la indemnización de perjuicios por daños.
} 
la aplicación de las reglas generales del derecho civil, como por disposición expresa de la Ley de Protección a los Consumidores (en adelante Ley del Consumidor, o simplemente LPC) que en su artículo $3^{\circ}$, inciso $1^{\circ}$, letra e) reconoce como uno de los derechos de los consumidores "la reparación e indemnización adecuada y oportuna de todos los daños materiales y morales en caso de incumplimiento de cualquiera de las obligaciones contraídas por el proveedor, y el deber de accionar de acuerdo a los medios que la ley le franquea".

El derecho sustantivo aplicable para obtener la reparación e indemnización de perjuicios ocasionados por infracciones al derecho de los consumidores -con excepción de lo que se dirá más adelante respecto a la extensión de los daños indemnizables-son las normas comunes contenidas en el Código Civil para determinar tanto la responsabilidad civil contractual como extracontractual, ${ }^{2}$ por lo tanto, su reparación deberá ajustarse a las reglas generales que rigen cada uno de estos estatutos. ${ }^{3}$

Como se sabe, al centro del régimen de la responsabilidad civil se encuentra la noción de daño, dado que su objeto es justamente, desde su función correctiva, reparar el perjuicio causado y, en consecuencia, éste es condición indispensable de los regímenes de responsabilidad civil romanistas, ${ }^{4}$ y a la vez, medida y límite de la reparación. ${ }^{5}$ En particular, en lo que refiere al daño moral o extrapatrimonial, a falta de un concepto

\footnotetext{
2 Contardo GonzÁlez, Juan Ignacio, “Artículo $3^{\circ}$ E)”, en: Barrientos, Francisca (coord.), De la Maza, Íñigo; Pizarro, Carlos (dir.), La protección de los derechos de los consumidores. Comentarios a la ley de protección a los derechos de los consumidores, Thomson Reuters, Santiago, 2013, pp. 123 y 124.

3 La principal diferencia entre estos dos regímenes que tiene relevancia en materia de derecho del consumo es el plazo de prescripción, que en materia contractual es de cinco años, mientras en extracontractual, de cuatro. Otras diferencias que la doctrina civilista ha identificado entre ambos regímenes (v.gr. CoRral Talciani, Hernán, Lecciones de responsabilidad civil extracontractual, Editorial Jurídica, Santiago, 2004, pp. 28-33) deben ser matizadas, especialmente en materia de derechos de los consumidores, por tres motivos: (i) existen muchas circunstancias en que los mismos hechos que constituyen un ilícito extracontractual pueden ser calificadas al mismo tiempo como incumplimientos contractuales, lo que se conoce como cúmulo o concurrencia de responsabilidades. En estas hipótesis, en algunos casos la doctrina y jurisprudencia han admitido el derecho de opción del demandante; (ii) lo anterior se ve reforzado en el caso de un estatuto protector como es el derecho del consumidor (Corte de Apelaciones de Talca, 2 de noviembre de 2011, Rol Nº62-2011, considerando $\left.6^{\circ}\right)$; y, (iii) por disposición expresa de la LPC, algunas de las normas del derecho contractual general no son aplicables o deben aplicarse con restricciones.

4 Domínguez Águila, Ramón, "Consideraciones en torno al daño en la responsabilidad civil. Una visión comparatista", Revista de Derecho Universidad de Concepción, 1990, Año LVII, № 188, p. 126.

5 Barros Bourie, Enrique, Tratado de responsabilidad extracontractual, Editorial Jurídica, Santiago, 2006, p. 215.
} 
en el derecho positivo, esta materia ha sido desarrollada en nuestro país por la jurisprudencia ${ }^{6} \mathrm{y}$, en términos generales, se define en oposición al daño económico o patrimonial, es decir, se trata del perjuicio causado sobre bienes de carácter no patrimonial. ${ }^{7}$

Desde su reconocimiento por la Excma. Corte Suprema en materia extracontractual el año $1922,{ }^{8}$ los tribunales superiores de justicia han seguido una tendencia de expansión del concepto de daño moral, encontrándose hoy superada la discusión sobre la procedencia de reparar este perjuicio cuando es fruto del incumplimiento contractual, reconocida ya largamente por la jurisprudencia. ${ }^{9}$ En derecho del consumo, en todo caso, a diferencia de lo que sucede en el derecho común, nunca se ha cuestionado que el daño moral es indemnizable cuando proviene de relaciones contractuales, en virtud del referido artículo $3^{\circ}$ inciso primero letra e) de la LPC, que habla de "todos los daños materiales y morales". ${ }^{10}$ No se trata, en todo caso, de una discusión resuelta, dado que siguen aún vigentes diversos debates doctrinales acerca de la naturaleza y límites del daño moral, es decir, cuáles son los bienes de carácter extrapatrimonial que pueden ser indemnizados en esta partida. Se ha discutido, por ejemplo, si el objeto de protección de la responsabilidad civil son derechos subjetivos o también meros intereses, siendo esta segunda posición defendida por la doctrina y jurisprudencia mayoritaria. ${ }^{11}$

Con esta definición amplia del daño moral, aparece la necesidad de delimitar cuáles son los intereses extrapatrimoniales cuya lesión da lugar a la responsabilidad civil, existiendo consenso en la doctrina que lo relevante es que se trate de un interés legítimo y significativo. ${ }^{12}$ Por su parte, el desarrollo particular de los intereses extrapatrimoniales que se encuentran comprendidos en la noción de daño moral ha sido realizado por la jurisprudencia. Tradicionalmente, éste se caracterizaba como

\footnotetext{
6 TAPia Rodríguez, Mauricio, Código Civil 1855-2005. Evolución y perspectivas, Editorial Jurídica, Santiago, 2005, p. 299.

7 Barros, cit. (n. 5), p. 287. En el mismo sentido, pp. Corral, cit (n. 3), pp. 148-149; RodríGuEz Grez, Pablo, Responsabilidad extracontractual, Editorial Jurídica, Santiago, 2002, p. 308; DomíngUEz Hidalgo, Carmen, El daño moral. Editorial Jurídica, Santiago, 2000, T. I, p. 84.

8 Corte Suprema, 16 de diciembre de 1922, RDJ, T. XXI, sec. $1^{\text {a }}$, p. 1053.

9 Domínguez Águila, cit. (n. 4), p. 84.

${ }^{10}$ Corte de Apelaciones de Antofagasta, 29 de junio de 2007, Rol № 49-2007, cons. $5^{\circ}$ y $6^{\circ}$.

11 Demarchi Salinas, María Victoria, "La persona jurídica como sujeto activo de la acción de indemnización de daño moral", Memoria para optar al grado de licenciado en ciencias jurídicas y sociales, Universidad de Chile, Santiago, no publicada, 2014, pp. 13-18.

${ }^{12}$ Barros, cit. (n. 5), pp. 222-228.
} 
pretium doloris, es decir, era equivalente al sufrimiento, ya sea físico o psíquico. Sin embargo, esa noción se encuentra superada, considerándose hoy que es sólo una de las categorías de perjuicios que, junto a otras, se encuentran comprendidas en la noción de daño extrapatrimonial. ${ }^{13}$ En efecto, actualmente, se entiende que el daño moral o extrapatrimonial no se encuentra limitado únicamente a la esfera espiritual o inmaterial de los sentimientos, como su nombre parece sugerir, sino que tiene un significado más amplio, que comprende varias categorías de perjuicios no avaluables en dinero que la jurisprudencia ha ido integrando progresivamente. ${ }^{14} \mathrm{En}$ este sentido, hay dos categorías de daños extrapatrimoniales especialmente relevantes: (i) las consecuencias extrapatrimoniales del daño corporal ${ }^{15} \mathrm{y}$ (ii) las lesiones a los derechos de la personalidad. ${ }^{16}$

Estas categorías, sin embargo, a diferencia de lo que ocurre en los derechos comparados de los que provienen, tienen poca relevancia al momento de valorizar el daño moral, ya que la jurisprudencia tiende a realizar cuantificaciones globales de los daños extrapatrimoniales, sin hacerse cargo de lo que estas distinciones implican. Por lo demás, los tribunales superiores de justicia han fallado reiteradamente que la cuantificación del daño moral es un asunto prudencial que corresponde determinar a los jueces de instancia, quedando así fuera de control vía casación. Ello ha significado que esta materia se encuentra cruzada por una gran subjetividad, lo que impide

\footnotetext{
${ }^{13}$ Barrientos Zamorano, Marcelo, "Del daño moral al daño extrapatrimonial: la superación del pretium doloris", Revista Chilena de Derecho, 2008, V. 35, N 1, pp. 85-106.

${ }^{14}$ Domínguez Águila, cit. (n. 4), pp. 78 y 79.

${ }^{15}$ El "daño corporal", es decir, la afectación a la integridad física típicamente producirá tanto daños patrimoniales como extrapatrimoniales. Entre las consecuencias extrapatrimoniales del daño corporal se encuentra, por un lado, el pretium doloris o aflicción física y mental; y, por otro, la imposibilidad futura de disfrutar de los placeres de la vida, que se conoce como "perjuicio de agrado" o "pérdida de ventajas de la vida" y se asimila al lucro cesante en materia patrimonial (BARRos, cit. (n. 5), pp. 319-325). La doctrina chilena también ha reconocido otras clases de perjuicios generados por el daño corporal, cuya formulación proviene de derechos comparados, como el perjuicio estético, el perjuicio sexual y el perjuicio de afecto familiar (BARros, cit. (n. 5), p. 290).

${ }^{16}$ El reconocimiento del daño moral como lesión a los derechos de la personalidad es consecuencia de la creciente prioridad otorgada al individuo, manifestada en la ampliación del concepto de daño moral y del hecho de que todos estos atributos deben ser considerados como intereses legítimos cuya lesión puede dar lugar a la indemnización de perjuicios, y así lo sostiene de manera generalizada la jurisprudencia que, a pesar de la limitación expresa de los daños indemnizables por expresiones injuriosas establecida en el artículo 2331 del Código Civil, ha dado especial protección a la honra, honor y privacidad (BARROS, cit. (n. 5), p. 544 y p. 579), la que ha sido incluso justificada constitucionalmente (Diez Schwerter, José Luis, El daño extracontractual. Jurisprudencia y doctrina, Editorial Jurídica de Chile, Santiago, 2002, p. 149).
} 
estandarizar los montos de indemnización, ${ }^{17}$ característica que también se ve reflejada en las sentencias condenatorias por infracción a los derechos de los consumidores estudiadas en este trabajo.

En materia de derechos de los consumidores, la Ley del Consumidor sólo permitía perseguir la reparación del daño moral en acciones individuales, seguidas ante Juzgados de Policía Local, excluyendo expresamente su reparación en acciones colectivas en el artículo $51 \mathrm{~N}^{\circ} 2$ del mismo cuerpo legal. Sin embargo, con la entrada en vigencia de la Ley $\mathrm{N}^{\circ} 21.081,{ }^{18}$ que modifica la LPC, se permite la indemnización del daño extrapatrimonial igualmente en procedimientos para la protección de los intereses colectivos y difusos de los consumidores. ${ }^{19-20} \mathrm{Si}$ bien se entiende que el daño moral es individual, toda vez que está ligado a la vivencia personal de cada consumidor, el reconocimiento de la posibilidad de indemnizar estos daños en un juicio colectivo supone también la existencia de ciertos hechos que a la generalidad de las personas le producen necesariamente un daño extrapatrimonial y que, por ende, éste puede ser de alguna forma estandarizado, tal como lo anticipa la Ley $\mathrm{N}^{\circ} 21.081$ al contemplar la determinación de un "mínimo común de indemnización".

Dada la escasa uniformidad que existe en la jurisprudencia respecto a elementos esenciales del daño moral y a la cuantificación de las

${ }^{17}$ Barros, cit. (n. 5), pp. 313-317.

${ }^{18}$ Ley 21.081 de 2018. Publicada en el Diario Oficial el 13 de septiembre de 2018 y, en lo pertinente, entró en vigencia el 14 de marzo de 2019.

${ }^{19}$ La Ley N²1.081 modificó el artículo $51 \mathrm{~N}^{\circ} 2$ de la LPC estableciendo expresamente que las indemnizaciones en los juicios colectivos podrán extenderse al daño moral, pero sólo en aquellos casos en los que se hayan afectado la integridad física o síquica o la dignidad de los consumidores, lo que deberá ser probado. Para su determinación, el tribunal podrá establecer un mínimo común de indemnización, para lo cual podrá ordenar un peritaje especial que será de cargo del infractor. Se crea un sistema de registro rápido y expedito ante el Servicio Nacional del Consumidor ("SERNAC") para que los consumidores potencialmente afectados puedan acceder a esta indemnización. En caso de no estar de acuerdo con el monto mínimo común, el consumidor podrá perseguir una indemnización mayor en un juicio individual posterior pudiendo optar entre seguirlo ante el mismo tribunal, en un procedimiento sumario sin reconvención o ante el JPL competente. Finalmente se dispone que el proveedor podrá efectuar una propuesta de indemnización o reparación del daño moral, la que considerará un mínimo común para todos los consumidores afectados.

${ }^{20}$ Esta modificación fue largamente cuestionada durante la discusión parlamentaria, donde los principales argumentos esgrimidos por sus detractores apuntaban (i) al carácter personalísimo del daño moral y (ii) a la diversa entidad de éste entre los distintos consumidores afectados, sugiriendo que no sería conveniente su indemnización en un procedimiento de esta naturaleza. Finalmente, y luego de una larga tramitación legislativa, se aprobó esta modificación en pro de los principios de reparación íntegra y oportuna de todos los daños materiales y morales (consagrado en el artículo $3^{\circ}$ inciso primero letra e) de la LPC) y de economía procesal. 
indemnizaciones de perjuicios otorgadas por esta partida, y la ausencia de jurisprudencia que otorgue daños morales colectivos, el estudio y sistematización de casos de protección del interés individual de los consumidores es un ejercicio útil para conocer los criterios utilizados por los tribunales en algunas materias recurrentes en derecho del consumo. Se estima que estos antecedentes podrían ser de utilidad no sólo para la resolución de casos individuales, sino también para la construcción de estándares para determinar los referidos mínimos comunes a la hora de indemnizar daños morales colectivos.

De acuerdo con lo anterior, en este trabajo se pretende identificar, a partir del análisis de la determinación del daño moral en casos individuales de infracción a la Ley del Consumidor, si existen criterios generales que permitan estandarizar ciertos elementos que configuran el daño moral y asociarlos a tipologías de hechos infraccionales y montos promedio de indemnización. Para ello, el análisis se centra en la revisión de dichos elementos en sentencias de JPL en juicios individuales por infracción a la LPC. ${ }^{21}$

\section{RESULTADOS DE LA INVESTIGACIÓN: CONFIGURACIÓN DEL DAÑO MORAL INDEMNIZADO EN SENTENCIAS PRONUNCIADAS EN CAUSAS INDIVIDUALES DE PROTECCIÓN DE LOS DERECHOS DE LOS CONSUMIDORES EJECUTORIADAS EL AÑO 2017}

El universo total de sentencias analizadas en este trabajo corresponde a 842 sentencias de protección de los derechos individuales de los consumidores, que quedaron firmes y ejecutoriadas el año 2017. ${ }^{22}$ Respecto a cada una de estas sentencias, se revisó el tipo de acción interpuesta en cada caso y la decisión adoptada en la sentencia definitiva de primera instancia, concluyendo que en el total de los casos se dedujo demanda infraccional; mientras que en 515 casos se dedujo además demanda civil indemnizatoria, ${ }^{23}$

\footnotetext{
${ }^{21}$ La información analizada se encuentra disponible en: Lazcano Maturana, Magdalena; Toro CÁceres, Javiera, "Decisión sobre demanda civil de indemnización del daño moral en sentencias definitivas, firmes y ejecutoriadas dictadas en Chile el 2017, en causas de protección del interés individual de los consumidores" (base de datos), Mendeley Data, v1., 19 de octubre de 2018, disponible en línea: http:// dx.doi.org/10.17632/94ctwj4ntn.1 (consulta: 20 de noviembre de 2018).

${ }^{22}$ Para un detalle de la metodología utilizada para determinar este universo, véase el Anexo 1 de este trabajo.

${ }^{23}$ En tres casos, las sentencias no contienen información respecto a si se presentó demanda civil indemnizatoria.
} 
de las cuales en 390 se solicitó indemnización de daño moral. ${ }^{24}$

La Tabla $\mathrm{N}^{\circ} 1$ da cuenta de la decisión de los tribunales en las sentencias de primera instancia, respecto de cada una de las acciones interpuestas:

\section{TABLA $N^{\circ} 1$}

Decisión de las sentencias de primera instancia respecto de la denuncia infraccional, la demanda civil de daño patrimonial y la demanda civil de daño moral, dictadas en procedimientos de protección individual de los derechos de los consumidores, que quedaron firmes y ejecutoriadas durante el año 2017

\begin{tabular}{|c|c|c|c|}
\hline & $\begin{array}{c}\text { Denuncia } \\
\text { infraccional }\end{array}$ & $\begin{array}{c}\text { Demanda civil daño } \\
\text { patrimonial }\end{array}$ & $\begin{array}{c}\text { Demanda civil daño } \\
\text { moral }\end{array}$ \\
\hline Acoge & 452 & 164 & 152 \\
\hline Rechaza & 311 & 220 & 200 \\
\hline Conciliación & NA & 111 & 38 \\
\hline TOTAL & $763^{25}$ & 495 & 390 \\
\hline
\end{tabular}

A continuación, el análisis se centra en las 390 sentencias que resolvieron conflictos en que se demandó el daño extrapatrimonial y, en particular, en aquellas que acogieron el daño moral demandado. Respecto a éstas, en primer lugar, se revisó la decisión de los tribunales en cuanto a concederla o rechazarla (2.1); y, en segundo lugar, respecto de aquellas sentencias que concedieron la indemnización, se analizaron los hechos infraccionales que causaron daño y dieron lugar a la indemnización de perjuicios $^{26}(2.2)$, los elementos que fueron considerados por los jueces para

\footnotetext{
${ }^{24}$ Debido a que en algunos casos los fallos resuelven la demanda civil sin exponer cuál es el daño demandado, existen 45 casos adicionales en que no existe información respecto a si se solicitó o no la indemnización del daño extrapatrimonial.

${ }^{25}$ Este total es inferior a los 842 casos en que se interpuso denuncia infraccional, debido a que existen 79 casos en que, habiéndose producido un acuerdo conciliatorio entre las partes respecto a la responsabilidad civil, el tribunal lo aprobó sin pronunciarse sobre la acción infraccional.

${ }^{26}$ Se revisaron también los artículos de la LPC que se dieron por infringidos, identificando respecto de cada sentencia, los artículos que fueron mencionados. Sin embargo, los resultados de este análisis no fueron significativos ya que la mayor parte de las sentencias citan artículos de la LPC que se refieren a infracciones genéricas, como el artículo $3^{\circ}$, que establece los derechos de los consumidores (70 sentencias); el artículo 12, que se refiere a la obligación del proveedor de respetar lo ofrecido o convenido (69 sentencias); y, el artículo 23 que consagra el deber de profesionalidad del proveedor (126 sentencias).
} 
otorgar la indemnización del daño moral (2.3), y, la cuantificación de las indemnizaciones otorgadas por este concepto (2.4). ${ }^{27}$

\subsection{Decisión de los tribunales respecto de la indemnización del daño moral}

En primer lugar, se revisó la decisión tomada por los tribunales en las 390 sentencias que se pronunciaron sobre las demandas de indemnización de daño extrapatrimonial, distinguiendo si en ellas éste se acogió ("acoge"), se rechazó ("rechaza") o bien si la causa terminó por un acuerdo conciliatorio entre las partes, no habiendo en dichos casos pronunciamiento del tribunal respecto de la indemnización del daño moral ("conciliación"). Dentro de las sentencias que fueron clasificadas como "rechaza", se comprenden todas aquellas en que no se concede la indemnización del daño moral, sin distinguir el motivo, incluyéndose entre ellas (i) aquellas en que, habiéndose concedido la acción infraccional, se rechaza expresamente la indemnización del daño moral (51 sentencias de primera instancia); y (ii) aquellas en las que no se da lugar a la infracción y por ende se rechaza la demanda de indemnización de perjuicios por faltar uno de los requisitos de la responsabilidad civil (149 sentencias de primera instancia), comprendiendo dentro de ellas, aquellas en que el tribunal se declara incompetente de oficio para conocer el asunto y no se pronuncia sobre el fondo de la causa, y las que acogen una excepción que pone término al juicio sin resolver el asunto controvertido.

A partir de lo anterior, se pudo identificar que, del total de 390 sentencias firmes y ejecutoriadas analizadas, 141 concedieron el daño moral demandado; 205 lo rechazaron; y, 44 juicios terminaron por acuerdo conciliatorio entre las partes. ${ }^{28}$ La siguiente Tabla $\mathrm{N}^{\circ} 2$ y el Gráfico $\mathrm{N}^{\circ} 1$ resumen lo señalado anteriormente:

\footnotetext{
${ }^{27}$ Respecto de cada una de estas sentencias, se revisaron las sentencias pronunciadas en segunda instancia cuando se interpuso recurso de apelación, y por ende los resultados que se exponen corresponden a los de las sentencias firmes y ejecutoriadas. Se revisaron también las sentencias pronunciadas por la Corte Suprema con ocasión de los recursos de queja presentados en contra de la sentencia de segunda instancia, sin embargo, no fueron consideradas en los resultados expuestos dado que solo en una de ellas se modificó la decisión respecto del daño moral.

${ }^{28}$ Se hace presente que en 202 casos se interpuso recurso de apelación en contra de la sentencia del JPL $\mathrm{y}$, adicionalmente, en 12, se interpuso recurso de queja en contra de la sentencia de segunda instancia.
} 


\section{TABLA No2}

Decisión sobre la demanda civil de daño moral dictadas en procedimientos de protección individual de los derechos de los consumidores, que quedaron firmes y ejecutoriadas durante el año 2017

\begin{tabular}{|c|c|c|c|}
\hline Decisión & $\begin{array}{c}\text { Sentencias de primera } \\
\text { instancia }\end{array}$ & $\begin{array}{c}\text { Sentencias firmes y } \\
\text { ejecutoriadas }\end{array}$ & $\begin{array}{c}\text { Sentencias firmes y } \\
\text { ejecutoriadas, tras la revisión de } \\
\text { los recursos de queja }\end{array}$ \\
\hline Acoge & 152 & 141 & 142 \\
\hline Rechaza & 200 & 205 & 204 \\
\hline Conciliación & 38 & 44 & 44 \\
\hline
\end{tabular}

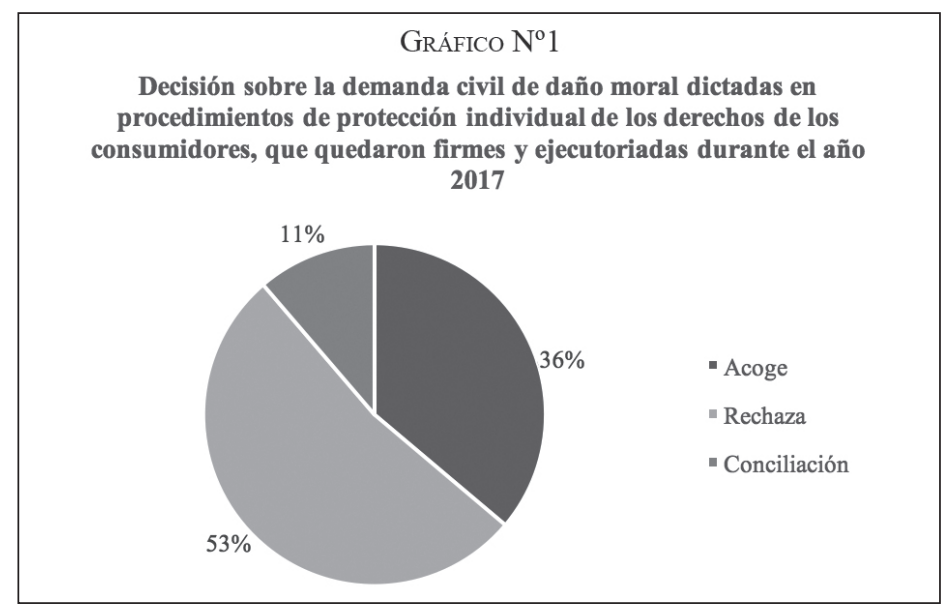

\subsection{Hechos infraccionales que dan lugar a la indemnización del daño moral}

Respecto de las 141 sentencias que acogieron el daño moral, se identificaron las infracciones que dieron lugar a la responsabilidad civil y la indemnización del daño moral, de acuerdo con la calificación realizada por los tribunales. A partir de lo anterior, se infirieron inductivamente las 17 categorías de hechos infraccionales que a continuación se detallan y se clasificaron las sentencias dentro de estas categorías: ${ }^{29}$ (i) accidentes en las

\footnotetext{
${ }^{29}$ Todas las sentencias fueron clasificadas dentro de una sola categoría de hecho infraccional, sin perjuicio de que algunas de ellas se referían a más de una, en cuyo caso se clasificó en la categoría que aparecía como más determinante para conceder el daño moral de acuerdo con lo expresado en la propia sentencia.
} 
dependencias del proveedor, (ii) cobros injustificados, (iii) discriminación y trato indigno en los sistemas de seguridad y vigilancia, (iv) envío o mantención injustificada en boletín comercial, (v) falta de información veraz y oportuna, (vi) fraudes bancarios o financieros, (vii) incumplimiento de las condiciones ofrecidas y/o contratadas, (viii) interrupción / suspensión injustificada de servicio, (ix) negligencia en servicios sanitarios que causa daños, (x) pérdida / daño de equipaje, (xi) producto defectuoso y/o incumplimiento garantía, (xii) retardo / no entrega de una encomienda, (xiii) retardo en la entrega de un producto comprado, (xiv) robo / pérdida de pertenencias dejadas en custodia o lockers del proveedor, (xv) robo y daños al vehículo en estacionamiento, (xvi) servicio defectuoso y (xvii) otros. La Tabla $\mathrm{N}^{\circ} 3$ siguiente da cuenta de los resultados de esta clasificación, ordenados según frecuencia:

\section{TABLA N³}

Número de sentencias definitivas, firmes y ejecutoriadas durante el año 2017, dictadas en procedimientos de protección individual de los derechos de los consumidores, que conceden el daño moral demandado, según hecho infraccional acreditado

\begin{tabular}{|l|c|}
\hline Hechos infraccionales & No de sentencias \\
\hline Producto defectuoso y/o incumplimiento garantía & 29 \\
\hline Robo y daños al vehículo en estacionamiento & 23 \\
\hline Incumplimiento de las condiciones ofrecidas y/o contratadas & 15 \\
\hline Cobros injustificados & 12 \\
\hline Pérdida / daño de equipaje & 10 \\
\hline Fraudes bancarios o financieros & 9 \\
\hline Discriminación y trato indigno en los sistemas de seguridad y vigilancia & 6 \\
\hline Envío o mantención injustificada en boletín comercial & 6 \\
\hline Otros & 6 \\
\hline Retardo / no entrega de una encomienda & 5 \\
\hline Accidentes en las dependencias del proveedor & 4 \\
\hline Interrupción / suspensión injustificada de servicio & 4 \\
\hline Retardo en la entrega de un producto comprado & 3 \\
\hline Incumplimiento de obligación de alzamiento de hipoteca dentro de plazo & 2 \\
\hline Negligencia en servicios sanitarios que causa daños & 141 \\
\hline Robo / pérdida de pertenencias dejadas en custodia o lockers del proveedor & 2 \\
\hline Servicio defectuoso & 2 \\
\hline Falta de información veraz y oportuna & 2 \\
\hline Total & 1 \\
\hline
\end{tabular}




\subsection{Elementos que configuran el daño moral indemnizado}

Igualmente, respecto de las 141 sentencias que acogieron el daño moral, se revisaron las expresiones empleadas por los jueces para justificar dicha indemnización. Fue posible observar que, en los distintos fallos, aun tratándose de distintos tribunales, se repiten las mismas o similares expresiones, en la mayoría de los casos sin un desarrollo o justificación de su empleo. A partir de ellas, se indujeron las siguientes cinco categorías de elementos que configuran el daño moral indemnizado, ${ }^{30}$ las que exceden la clásica dimensión del pretium doloris:

(i) Molestia o malestar: corresponde al sentido natural y obvio de estas expresiones, que, junto a otras similares, se reiteran textualmente en diversas sentencias, y es posible distinguirlas de otras expresiones de afectación psicológica de mayor entidad.

Ejemplos de esta categoría de daño moral son las siguientes expresiones, extractados de las sentencias analizadas: "molestias que naturalmente debió sufrir la actora";31 "padecimientos e incomodidades, que no habrían ocurrido de no mediar la actuación negligente de la demandada"; 32 y, "molestias, aflicción y menoscabo". ${ }^{33}$

(ii) Sufrimiento o aflicción psicológica: corresponde a la afectación psicológica o emocional de mayor entidad, donde se reúnen variadas expresiones utilizadas en las sentencias, tales como angustia, estrés, ansiedad, temor, incertidumbre, desconfianza, frustración y pesar, entre otros.

Ejemplos de las expresiones utilizadas para describir esta categoría de daño moral son las siguientes: "temor, aflicción y sufrimiento"; 34 "influyó

\footnotetext{
${ }^{30}$ Se hace presente que existen nueve sentencias en las que el tribunal no da argumentos para la indemnización del daño moral, sino que simplemente estima que concurre y corresponde indemnizarlo, determinando un monto de indemnización. Asimismo, en una sentencia el tribunal se refirió a la "pérdida de oportunidad" como elemento constitutivo del daño a indemnizar por concepto de daño moral, en circunstancias que dicho elemento corresponde más bien a un daño patrimonial.

${ }^{31} 2^{\circ}$ JPL de Antofagasta, 15 de diciembre de 2017, "Matilde Pinto Peña con “La Polar", Rol N¹0.6722017, disponible en Base de Datos SERNAC.

${ }^{32} 2^{\circ}$ JPL de Curicó, 23 de junio de 2016, "Surjan Vega con Administradora de Supermercados Express", Rol N³.888-2015, disponible en Base de Datos SERNAC.

${ }_{33} 1^{\circ}$ JPL de Talca, 24 de octubre de 2016, "Bravo con Hipermercados Tottus S.A.", Rol N572-2016, disponible en Base de Datos SERNAC.

${ }^{34}$ JPL de La Granja, 30 de enero de 2017, “SERNAC con CENCOSUD”, Rol N¹1.279-2016, disponible
} 
negativamente en su siquis"; 35 "afectación en lo emocional y anímico (...), natural estado de aflicción y detrimento psicológicos, consecuencial al hecho vivido"; ${ }^{36} \mathrm{y}$, "dolor espiritual, intranquilidad, congoja, angustia, al ver a su vástago sometiéndose a largos e interminables tratamientos de rehabilitación". ${ }^{37}$

(iii) Dolor físico: corresponde al dolor ocasionado por lesiones corporales. Las expresiones utilizadas en estas sentencias para describir el daño moral son: "menoscabo físico y psíquico"38 y "lesiones (físicas) de carácter grave". ${ }^{39}$

(iv) Afectación a la dignidad y a la honra: corresponde al daño a la imagen y prestigio del consumidor afectado que vulnera sus derechos a la dignidad y honra.

Ejemplos de esta categoría de daño moral son las siguientes expresiones: "atentado a la honra, dignidad y prestigio que la persona tiene frente a la sociedad y la sanción eventual de que por dichos antecedentes se pueda perder un trabajo o no obtenerlo"; "situación de vejación ante los demás clientes del establecimiento"; ${ }^{41} \mathrm{y}$, "es indudable que el hecho de estar registrado como moroso en alguna base de datos de carácter nacional, ya sea DICOM, SINACOFI u otras trae aparejado innumerables inconvenientes para quien figura en ella, pues deja de ser sujeto de crédito tanto en instituciones bancarias, como en casas comerciales". ${ }^{42}$

en Base de Datos SERNAC.

35 JPL de Quilicura, 21 de marzo de 2017, "SERNAC con Comercializadora S.A.”, Rol N³5.946-2016, disponible en Base de Datos SERNAC.

${ }^{36} 1^{\circ} \mathrm{JPL}$ de San Bernardo, 28 de julio de 2017, "Fuentes Valenzuela con Mall Plaza Sur”, Rol N¹.9752017, disponible en Base de Datos SERNAC.

$373^{\circ}$ JPL de Iquique, 14 de marzo de 2017, “Jeldres Cano con CENCOSUD Retail S.A.”, Rol N¹2.3292016, disponible en Base de Datos SERNAC.

$381^{\circ}$ JPL de Antofagasta, 6 de junio de 2017, "Carvajal Álvarez con Hipermercado Tottus S.A.”, Rol N4.687-2017, disponible en Base de Datos SERNAC.

39 JPL de Vallenar, 6 de abril de 2017, “González Bembow con Supermercados Unimarc S.A.”, Rol N9.232-2016, disponible en Base de Datos SERNAC.

$402^{\circ}$ JPL de Temuco, 11 de mayo de 2017, "Gutiérrez Scheitzer con Comercial Eccsa S.A.”, Rol $N^{\circ} 67.887-2016$, disponible en Base de Datos SERNAC.

${ }^{41} 2^{\circ}$ JPL de Temuco, 14 de diciembre de 2017, "Delgado Benavente con CENCOSUD S.A.”, Rol No79.305-2017, disponible en Base de Datos SERNAC.

$421^{\circ}$ JPL de Talca, 5 de abril de 2017, "Campos Pinochet con Banco de desarrollo de Scotiabank" (sic.), Rol N8-649-2011, disponible en Base de Datos SERNAC. 
(v) Alteración de la vida normal y pérdida de tiempo: corresponde a las gestiones o trámites que el consumidor se ve obligado a realizar para obtener la reparación de los daños sufridos con ocasión de la infracción cometida por el proveedor, lo que altera el curso normal de su vida diaria y le hace perder tiempo.

Ejemplos de las expresiones utilizadas para describir esta categoría de daño moral son: "la actora fue afectada en su calidad de vida por las diversas diligencias y trámites $a$ que se vio obligada"; 43 "pérdida de tiempo"; "los reclamos y denuncias que debió hacer, originados de un hecho ajeno a su responsabilidad, ante la demandada (...), luego ante instancias administrativas, SERNAC y Fiscalía Local de Concepción, frente a los cuales no obtuvo respuesta satisfactoria, naturalmente le afectaron su integridad física y emocional", ${ }^{45} \mathrm{y}$, "molestias y trastornos en su vida, además del tiempo empleado para poder obtener una solución y verse obligado a recurrir al tribunal para restablecer el imperio del derecho, tener que obtener y/o preparar documentación probatoria, todos trámites que no debería haber realizado de no mediar la conducta contravencional de la demandada". ${ }^{46}$

Respecto de cada sentencia, se identificaron todas las categorías que fueron mencionadas -varias de las sentencias refieren a más de una-, con el objeto de contabilizar el número de menciones que tuvo cada categoría. El Gráfico $\mathrm{N}^{\circ} 2$ siguiente da cuenta de las menciones a cada una de las categorías de daño moral recién descritas:

\footnotetext{
43 JPL de Ovalle, 12 de octubre de 2016, “Ahumada Pizarro con CENCOSUD Retail S.A.”, Rol $\mathrm{N}^{\circ} 8.577-2016$, disponible en Base de Datos SERNAC.

${ }^{44} 3^{\circ} \mathrm{JPL}$ de Temuco, 17 de abril de 2017, “Oses Alarcón contra Qing Lin Importadora”, Rol N${ }^{\circ} 31.029$ 2016, disponible en Base de Datos SERNAC.

$451^{\circ}$ JPL de Concepción, 23 de marzo de 2017, "Salamanca Godoy y otra con CAR S.A.", Rol $\mathrm{N}^{\circ} 21.627-2010$, disponible en Base de Datos SERNAC.

${ }^{46} 2^{\circ}$ JPL de Osorno, 13 de marzo de 2017, "Concha Burgos con Personal Computer Factory", Rol N5.278-2016, disponible en Base de Datos SERNAC.
} 


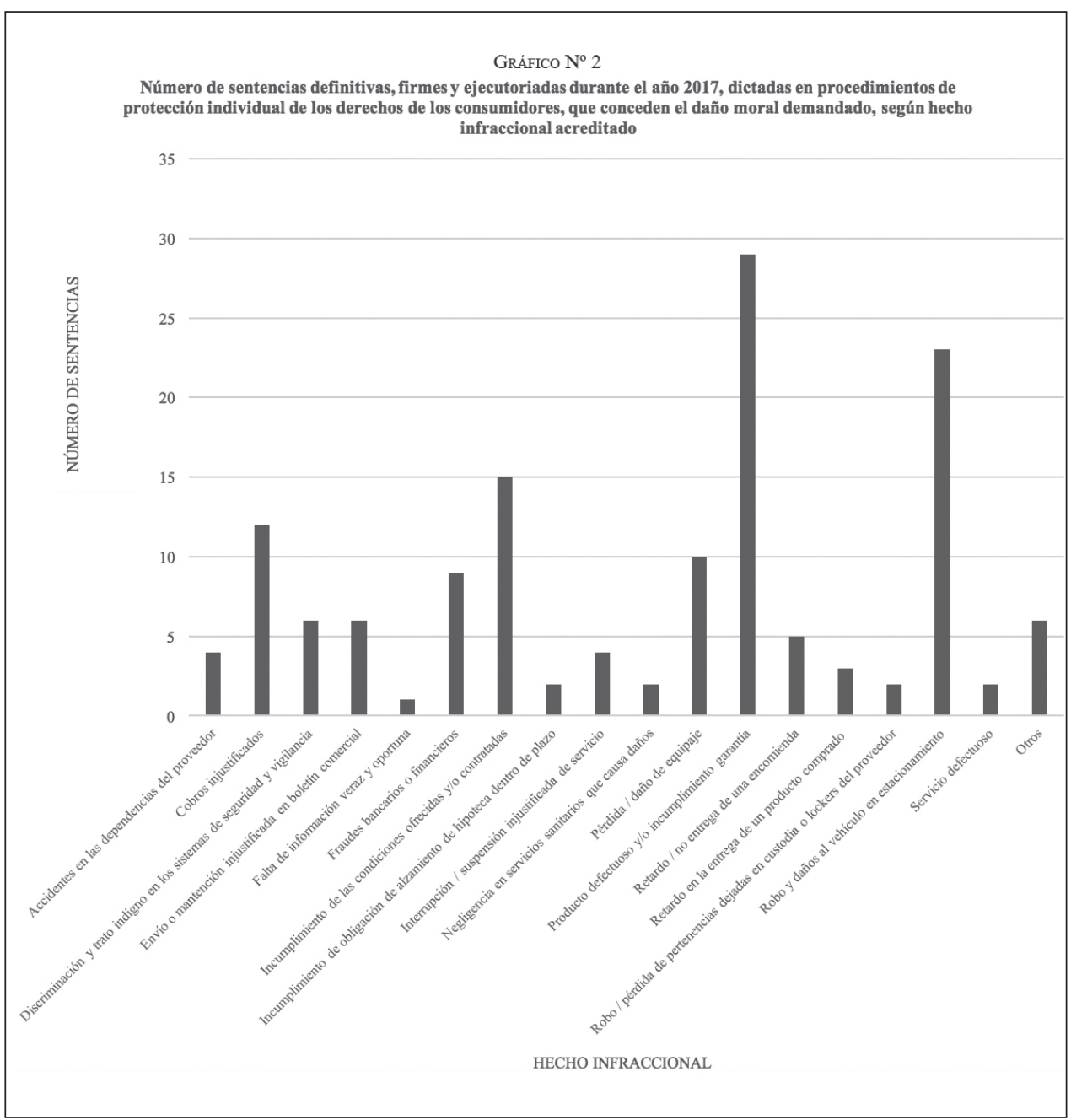

Por su parte, la Tabla $\mathrm{N}^{\circ} 4$ da cuenta de las categorías de elementos que configuran el daño moral mencionadas en las sentencias en relación con las categorías de hecho infraccional acreditado, y, a su vez, del total de menciones que tuvo cada categoría de elemento que configura el daño moral: 


\section{TABLA $\mathrm{N}^{\circ} 4$}

Elementos que configuran el daño moral concedido en sentencias definitivas, firmes y ejecutoriadas durante el año 2017, dictadas en procedimientos de protección individual de los derechos de los consumidores, según hecho infraccional acreditado

\begin{tabular}{|c|c|c|c|c|c|}
\hline \multirow[b]{2}{*}{ Hecho infraccional } & \multicolumn{5}{|c|}{$\mathbf{N}^{\circ}$ de sentencias según elemento que configura el daño moral } \\
\hline & $\begin{array}{c}\text { Molestia } \\
- \\
\text { malestar }\end{array}$ & $\begin{array}{l}\text { Sufrimiento } \\
\text { - aflicción } \\
\text { psicológica }\end{array}$ & $\begin{array}{l}\text { Dolor } \\
\text { físico }\end{array}$ & $\begin{array}{l}\text { Afectación a } \\
\text { la dignidad } \\
\text { y a la honra }\end{array}$ & $\begin{array}{c}\text { Alteración } \\
\text { de la vida } \\
\text { normal y } \\
\text { pérdida de } \\
\text { tiempo }\end{array}$ \\
\hline $\begin{array}{l}\text { Accidentes en las dependencias del } \\
\text { proveedor }\end{array}$ & 2 & 1 & 1 & 0 & 0 \\
\hline Cobros injustificados & 6 & 5 & 0 & 2 & 2 \\
\hline $\begin{array}{l}\text { Discriminación y trato indigno en los } \\
\text { sistemas de seguridad y vigilancia }\end{array}$ & 2 & 3 & 0 & 3 & 0 \\
\hline $\begin{array}{l}\text { Envío o mantención injustificada en } \\
\text { boletín comercial }\end{array}$ & 2 & 2 & 0 & 2 & 2 \\
\hline Falta de información veraz y oportuna & 0 & 0 & 0 & 0 & 0 \\
\hline Fraudes bancarios o financieros & 4 & 4 & 0 & 0 & 1 \\
\hline $\begin{array}{l}\text { Incumplimiento de las condiciones } \\
\text { ofrecidas y/o contratadas }\end{array}$ & 1 & 14 & 0 & 0 & 3 \\
\hline $\begin{array}{l}\text { Interrupción - suspensión injustificada } \\
\text { de servicio }\end{array}$ & 1 & 3 & 0 & 0 & 0 \\
\hline $\begin{array}{l}\text { Negligencia en servicios sanitarios que } \\
\text { causa daños }\end{array}$ & 1 & 1 & 0 & 0 & 0 \\
\hline Pérdida - daño de equipaje & 3 & 8 & 0 & 0 & 1 \\
\hline $\begin{array}{l}\text { Producto defectuoso } \quad \mathrm{y} / \mathrm{o} \\
\text { incumplimiento garantía }\end{array}$ & 13 & 13 & 0 & 0 & 6 \\
\hline Retardo - no entrega de una encomienda & 1 & 2 & 0 & 1 & 1 \\
\hline $\begin{array}{l}\text { Retardo en la entrega de un producto } \\
\text { comprado }\end{array}$ & 2 & 1 & 0 & 0 & 2 \\
\hline $\begin{array}{l}\text { Robo - pérdida de pertenencias dejadas } \\
\text { en custodia o lockers del proveedor }\end{array}$ & 0 & 2 & 0 & 0 & 0 \\
\hline $\begin{array}{l}\text { Robo y daños al vehículo en } \\
\text { estacionamiento }\end{array}$ & 11 & 16 & 0 & 0 & 5 \\
\hline Servicio defectuoso & 1 & 1 & 0 & 0 & 0 \\
\hline Otros & 1 & 2 & 0 & 0 & 1 \\
\hline Total & 51 & 78 & 1 & 8 & 24 \\
\hline
\end{tabular}


2.4. Cuantificación de las indemnizaciones de perjuicios por daño moral otorgadas

Por último, se analizó la cuantificación de la indemnización por daño moral otorgada, consignando respecto de cada una de las 141 sentencias que concedieron dicha indemnización, el monto otorgado en cada caso. Se hace presente que en aquellos casos en que hubo más de un demandante, se consignó el monto otorgado a cada persona.

En la siguiente Tabla $\mathrm{N}^{\circ} 5$ y en el Gráfico $\mathrm{N}^{\circ} 3$ se resumen los montos otorgados como indemnización de daño moral en relación con los hechos infraccionales acreditados.

\section{TABLA N5}

Montos de indemnización otorgados por concepto de daño moral en sentencias definitivas, firmes y ejecutoriadas durante el año 2017, dictadas en procedimientos de protección individual de los derechos de los consumidores, según hecho infraccional acreditado

\begin{tabular}{|c|c|c|c|}
\hline Hecho infraccional & Mínimo & Máximo & Promedio \\
\hline Accidentes en las dependencias del proveedor & $\$ 1.000 .000$ & $\$ 6.000 .000$ & $\$ 3.504 .065$ \\
\hline Cobros injustificados & $\$ 100.000$ & $\$ 600.000$ & $\$ 350.000$ \\
\hline $\begin{array}{l}\text { Discriminación y trato indigno en los sistemas de seguridad } \\
\text { y vigilancia }\end{array}$ & $\$ 200.000$ & $\$ 2.500 .000$ & $\$ 1.100 .000$ \\
\hline Envío o mantención injustificada en boletín comercial & $\$ 200.000$ & $\$ 8.000 .000$ & $\$ 2.916 .667$ \\
\hline Falta de información veraz y oportuna & $\$ 100.000$ & $\$ 100.000$ & $\$ 100.000$ \\
\hline Fraudes bancarios o financieros & $\$ 200.000$ & $\$ 1.500 .000$ & $\$ 483.333$ \\
\hline Incumplimiento de las condiciones ofrecidas y/o contratadas & $\$ 60.000$ & $\$ 2.000 .000$ & $\$ 602.000$ \\
\hline $\begin{array}{l}\text { Incumplimiento de obligación de alzamiento de hipoteca den- } \\
\text { tro de plazo }\end{array}$ & $\$ 100.000$ & $\$ 1.000 .000$ & $\$ 550.000$ \\
\hline Interrupción - suspensión injustificada de servicio & $\$ 100.000$ & $\$ 5.000 .000$ & $\$ 1.750 .000$ \\
\hline Negligencia en servicios sanitarios que causa daños & $\$ 2.000 .000$ & $\$ 2.500 .000$ & $\$ 2.250 .000$ \\
\hline Pérdida - daño de equipaje & $\$ 50.000$ & $\$ 5.000 .000$ & $\$ 1.095 .000$ \\
\hline Producto defectuoso y/o incumplimiento garantía & $\$ 30.000$ & $\$ 2.000 .000$ & $\$ 360.157$ \\
\hline Retardo - no entrega de una encomienda & $\$ 200.000$ & $\$ 500.000$ & $\$ 340.000$ \\
\hline Retardo en la entrega de un producto comprado & $\$ 100.000$ & $\$ 300.000$ & $\$ 200.000$ \\
\hline $\begin{array}{l}\text { Robo - pérdida de pertenencias dejadas en custodia o lockers } \\
\text { del proveedor }\end{array}$ & $\$ 100.000$ & $\$ 400.000$ & $\$ 250.000$ \\
\hline Robo y daños al vehículo en estacionamiento & $\$ 50.000$ & $\$ 2.000 .000$ & $\$ 629.565$ \\
\hline Servicio defectuoso & $\$ 100.000$ & $\$ 300.000$ & $\$ 200.000$ \\
\hline Otros & $\$ 150.000$ & $\$ 5.000 .000$ & $\$ 1.458 .333$ \\
\hline Total & $\$ 30.000$ & $\$ 8.000 .000$ & $\$ 824.261$ \\
\hline
\end{tabular}




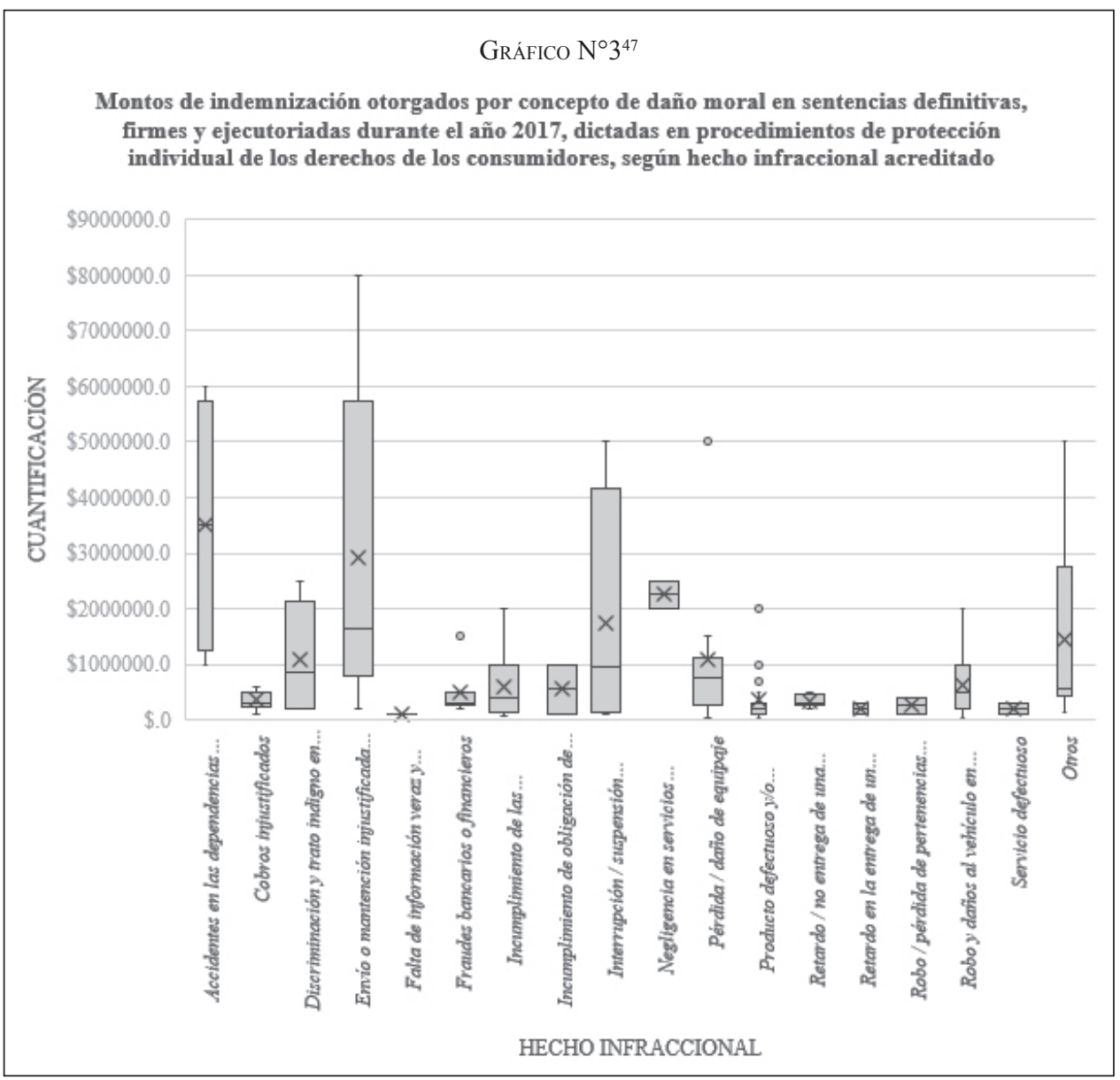

III. CONCLUSIONES

Del análisis de los resultados obtenidos en este trabajo, es posible extraer las siguientes conclusiones:

1.- Del total de sentencias revisadas, en el $59 \%$ de aquellas que se

${ }^{47}$ El Gráfico $\mathrm{N}^{\circ} 3$ es un diagrama de caja, que permite graficar la dispersión de los datos presentados. En éste, se muestra la distribución de datos en cuartiles, resaltando el promedio y los valores atípicos. La caja representa el rango en que se encuentra distribuido el 50\% de los resultados, mientras que la línea horizontal dentro de la caja representa la mediana y el valor marcado con " $\mathrm{X}$ ", el promedio. Las líneas verticales que se extienden desde la caja, lo hacen hasta los valores máximos y mínimos de cada serie, mientras que los puntos representan los valores atípicos. 
pronuncian sobre la acción infraccional, ésta fue concedida, rechazándose en el $41 \%$ restante.

2.- Del total de causas seguidas ante JPL por infracción de los derechos de los consumidores cuyas sentencias fueron revisadas, en el $46 \%$ de los casos se interpuso, junto con la acción infraccional, una acción de responsabilidad civil por daños extrapatrimoniales.

3.- Del total de demandas de indemnización del daño moral, el $36 \%$ de ellas fue acogida; el 53\%, rechazada; y, el 11\% de las causas terminaron por acuerdos conciliatorios entre las partes.

Cabe señalar que, de la revisión de las sentencias se desprende que la principal razón para no conceder la indemnización del daño moral es el rechazo de la acción infraccional (75\% en las sentencias de primera instancia). Asimismo, es posible advertir que, en la mayoría de los casos restantes, su rechazo dice relación con la falta de prueba, aunque los criterios relativos a la necesidad de prueba y el estándar probatorio exigido son muy diversos entre los distintos tribunales.

4.- Sólo el $24 \%$ de las sentencias de primera instancia revisadas fueron apeladas, quedando firmes sin revisión de un tribunal superior el $76 \%$ restante. Cabe destacar que, aun en el caso de las sentencias apeladas, los resultados globales respecto de la acción civil de daño extrapatrimonial (calificación y cuantificación del daño), no varían significativamente con la decisión de las Cortes de Apelaciones, lo que permite deducir que, en general, coinciden con los criterios de los JPL.

5.- Casi la totalidad de las infracciones que dan lugar a la indemnización del daño moral pueden ser agrupadas en 17 categorías de hechos infraccionales, siendo las más comunes "producto defectuoso y/o incumplimiento garantía" (20,6\%), "robo y daños al vehículo en estacionamiento" (16,3\%), "incumplimiento de las condiciones ofrecidas y/o contratadas" $(10,6 \%)$, "cobros injustificados" $(8,5 \%)$ y "pérdida - daño de equipaje" (7,1\%).

6.- Los principales elementos que son considerados por los tribunales como constitutivos de daño moral indemnizable pueden ser clasificados en cinco categorías: (i) molestia - malestar, (ii) sufrimientos - aflicción 
psicológica, (iii) dolor físico, (iv) afectación a la dignidad y a la honra y (v) alteración de la vida normal y pérdida de tiempo, siendo las dos primeras categorías las más aludidas.

Si bien el componente de afectación psicológica, relacionado con el clásico pretium doloris es predominante, se puede advertir la recepción de nuevas categorías que escapan de dicha concepción tradicional de daño moral. En particular, destaca el reconocimiento de la alteración de la vida normal y pérdida de tiempo, inherentes a la obtención de la reparación ante infracciones de los derechos de los consumidores, como un perjuicio extrapatrimonial.

7.- Del total de las sentencias que conceden la indemnización del daño moral, el promedio de las indemnizaciones otorgadas por esta partida es de $\$ 824.261$, siendo la más baja de $\$ 30.000$ y la mayor, de $\$ 8.000 .000$.

Sin perjuicio que el universo de sentencias analizadas es insuficiente para extraer conclusiones categóricas relativas a la indemnización según hechos infraccionales, se puede advertir que aquellos que dieron lugar a los mayores montos de indemnización corresponden a "accidentes en las dependencias del proveedor" (en promedio, \$3.500.000), “envío o mantención injustificada en el boletín comercial" (en promedio, \$3.460.000) y "negligencia en servicios sanitarios que causa daños" (en promedio, \$2.250.000). Por su parte, los montos de indemnización más bajos corresponden a "falta de información veraz y oportuna" (en promedio, \$100.000), "retardo en la entrega de un producto comprado" (en promedio, \$200.000) y, "servicio defectuoso" (en promedio, \$200.000).

\section{BIBLIOGRAFÍA CITADA}

\section{1) Doctrina}

Andrade RAmírez, Víctor, "Derecho del consumo. Un breve relato sobre sus fundamentos teóricos, desarrollos y nuevas tendencias", Memoria para optar al grado de licenciado en ciencias jurídicas y sociales, Universidad de Chile, Santiago, no publicada, 2015, 174 pp.

BARrientos ZAMORANO, Marcelo, "Del daño moral al daño extrapatrimonial: la superación del pretium doloris”, Revista Chilena de Derecho, 2008, V. 35, N 1 , pp. 85-106.

Barros Bourie, Enrique, Tratado de responsabilidad extracontractual, Editorial Jurídica, Santiago, 2006, 1230 pp. 
Contardo González, Juan Ignacio, “Artículo $3^{\circ}$ E)”, en: Barrientos Camus, Francisca (coord.), De la Maza Gazmuri, Íñigo y Pizarro Wilson, Carlos (dir.), La protección de los derechos de los consumidores. Comentarios a la ley de protección a los derechos de los consumidores, Thomson Reuters, Santiago, 2013, pp. 117132.

Corral Talciani, Hernán, Lecciones de responsabilidad civil extracontractual, Editorial Jurídica, Santiago, 2003, 498 pp.

Demarchi Salinas, María Victoria, "La persona jurídica como sujeto activo de la acción de indemnización de daño moral", Memoria para optar al grado de licenciado en ciencias jurídicas y sociales, Universidad de Chile, Santiago, 2014, no publicada, $138 \mathrm{pp}$.

Diez Schwerter, José Luis, El daño extracontractual. Jurisprudencia y doctrina, Editorial Jurídica, Santiago, 2002, $1^{\circ}$ reimpresión, 291 pp.

Domínguez Águila, Ramón, "Consideraciones en torno al daño en la responsabilidad civil. Una visión comparatista", Revista de Derecho Universidad de Concepción, 1990, Año LVII, N 188, pp. 125-168.

Domínguez Hidalgo, Carmen, El daño moral, Editorial Jurídica, Santiago, 2000, T. I, 782 pp.

Rodríguez Grez, Pablo, Responsabilidad extracontractual, Editorial Jurídica, Santiago, 2002, 505 pp.

Tapia Rodríguez, Mauricio, Código Civil 1855-2005. Evolución y perspectivas, Editorial Jurídica, Santiago, 2005, 471 pp.

\section{2) Información administrativa}

Servicio Nacional del Consumidor, Estadística anual 2017. Registro Nacional de Sentencias Servicio Nacional del Consumidor, SERNAC, Santiago, 2018, 36 pp.

Servicio Nacional del Consumidor (División Jurídica), Oficio Ordinario $N^{\circ} 9496$, de 29 de mayo de 2018.

Servicio Nacional del Consumidor (División Jurídica), Oficio Ordinario $N^{\circ} 9497$, de 29 de mayo de 2018.

\section{3) Bases de datos}

Lazcano Maturana, Magdalena; Toro Cáceres, Javiera, "Decisión sobre demanda civil de indemnización del daño moral en sentencias definitivas, firmes y ejecutoriadas dictadas en Chile el 2017, en causas de protección del interés individual de los consumidores" (base de datos), Mendeley Data, v1., 19 de 
octubre de 2018, en línea: http://dx.doi.org/10.17632/94ctwj4ntn.1 (consulta: 20 de noviembre de 2018).

Servicio Nacional del Consumidor (eds.), "Registro Público de Sentencias", documento disponible en línea:, consulta: 20 de noviembre de 2018.

\section{4) Jurisprudencia}

Corte Suprema, 16 de diciembre de 1922, RDJ, T. XXI, sec. $1^{\text {a }}$, p. 1053.

Corte de Apelaciones de Antofagasta, 29 de junio de 2007, Rol N 49-2007.

Corte de Apelaciones de Talca, 2 de noviembre de 2011, Rol N 692-2011.

$2^{\circ}$ JPL de Curicó, 23 de junio de 2016, "Surjan Vega con Administradora de Supermercados Express", Rol N³.888-2015, disponible en Base de Datos SERNAC.

$1^{\circ}$ JPL de Talca, 24 de octubre de 2016, "Bravo con Hipermercados Tottus S.A.”, Rol N572-2016, disponible en Base de Datos SERNAC.

JPL de La Granja, 30 de enero de 2017, "SERNAC con CENCOSUD", Rol N¹1.279-2016, disponible en Base de Datos SERNAC.

JPL de Quilicura, 21 de marzo de 2017, "SERNAC con Comercializadora S.A.”, Rol N³5.946-2016, disponible en Base de Datos SERNAC.

$2^{\circ}$ JPL de Osorno, 13 de marzo de 2017, "Concha Burgos con Personal Computer Factory”, Rol N5.278-2016, disponible en Base de Datos SERNAC.

$3^{\circ}$ JPL de Iquique, 14 de marzo de 2017, "Jeldres Cano con CENCOSUD Retail S.A.”, Rol N¹2.329-2016, disponible en Base de Datos SERNAC.

$1^{\circ}$ JPL de Concepción, 23 de marzo de 2017, "Salamanca Godoy y otra con CAR S.A.”, Rol N²1.627-2010, disponible en Base de Datos SERNAC.

$1^{\circ}$ JPL de Talca, 5 de abril de 2017, "Campos Pinochet con Banco de desarrollo de Scotiabank" (sic.), Rol N8-649-2011, disponible en Base de Datos SERNAC.

JPL de Vallenar, 6 de abril de 2017, "González Bembow con Supermercados Unimarc S.A.”, Rol N9.232-2016, disponible en Base de Datos SERNAC.

$3^{\circ}$ JPL de Temuco, 17 de abril de 2017, "Oses Alarcón contra Qing Lin Importadora”, Rol N¹31.029-2016, disponible en Base de Datos SERNAC.

$2^{\circ}$ JPL de Temuco, 11 de mayo de 2017, "Gutiérrez Scheitzer con Comercial Eccsa S.A.”, Rol N67.887-2016, disponible en Base de Datos SERNAC.

$1^{\circ}$ JPL de Antofagasta, 6 de junio de 2017, "Carvajal Álvarez con Hipermercado Tottus S.A.”, Rol N4.687-2017, disponible en Base de Datos SERNAC.

$1^{\circ}$ JPL de San Bernardo, 28 de julio de 2017, "Fuentes Valenzuela con Mall Plaza Sur", Rol N¹.975-2017, disponible en Base de Datos SERNAC.

JPL de Ovalle, 12 de octubre de 2016, "Ahumada Pizarro con CENCOSUD 
Retail S.A.”, Rol N8.577-2016, disponible en Base de Datos SERNAC.

$2^{\circ}$ JPL de Temuco, 14 de diciembre de 2017, "Delgado Benavente con CENCOSUD S.A.”, Rol N79.305-2017, disponible en Base de Datos SERNAC.

$2^{\circ}$ JPL de Antofagasta, 15 de diciembre de 2017, "Matilde Pinto Peña con “La Polar", Rol N¹0.672-2017, disponible en Base de Datos SERNAC.

\section{5) Normas legales}

Ley $\mathrm{N}^{\circ} 19.496$, sobre protección de los derechos de los consumidores, 1997. Ley N²1.081, que modifica la Ley N¹9.496 sobre Protección de los Derechos de los Consumidores, 2018.

Código Civil.

\section{6) Anexos}

Anexo 1: Descripción del universo de sentencias analizadas.

AnEXo 2: Listado de sentencias definitivas, firmes y ejecutoriadas durante el año 2017, que conceden el daño moral demandado en causas de protección del interés individual de los consumidores.

\section{ANEXO 1}

\section{Descripción del universo de sentencias analizadas}

En primer lugar, se hace presente que una de las dificultades enfrentadas al realizar este estudio es que no existe una base de datos sistemática que permita un acceso expedito a las sentencias de primera instancia dictadas por los JPL en juicios de protección de los consumidores. Si bien el SERNAC tiene la obligación de llevar un Registro Público de Sentencias, ${ }^{48}$ al que se

\footnotetext{
${ }^{48}$ Por disposición del artículo 58 letra e) en relación con el artículo 58 bis de la Ley del Consumidor, el SERNAC tiene la obligación de llevar un registro público de las sentencias definitivas y las sentencias interlocutorias que fallen cuestiones de competencia ejecutoriadas dictadas por los jueces de letras y los jueces de policía local en materias reguladas por la LPC.
} 
accede a través de su sitio web, ${ }^{49}$ el buscador arroja resultados incompletos. ${ }^{50}$

Debido a lo anterior, con el objeto de acceder a estas sentencias, se realizaron dos solicitudes de transparencia al SERNAC - una relativa a la Región Metropolitana y otra respecto a todas las demás regiones-, en virtud de la Ley $\mathrm{N}^{\circ} 20.285$ sobre acceso a la información pública, requiriendo las sentencias firmes y ejecutoriadas durante el año 2017 remitidas al Registro Público de Sentencias. ${ }^{51}$ En ambos casos, el SERNAC respondió las solicitudes señalando que la información solicitada "se encuentra permanentemente a disposición del público en su sitio web, sección 'Registro de Sentencias Judiciales". A pesar de lo anterior, "con el fin de facilitar la búsqueda", adjuntó archivos que individualizan las sentencias, señalando respectivamente que "se adjunta tabla Excel, que da cuenta de 255 sentencias ejecutoriadas en el año 2017 respecto de la Región Metropolitana, información desagregada por: año de inicio, número de rol, número de Ingreso Corte de Apelaciones y Juzgado de Policía Local" y2 "se adjunta tabla Excel, que da cuenta de 623 sentencias ejecutoriadas en el año 2017 respecto de las regiones del país a excepción de la Metropolitana, información desagregada por: año de inicio, número de rol, número de Ingreso Corte de Apelaciones y Juzgado de Policía Local", ${ }^{53}$ resultando en un total de 878 sentencias. ${ }^{54}$

\footnotetext{
${ }^{49}$ Servicio Nacional del Consumidor (eds.), "Registro Público de Sentencias", documento disponible en línea: https://www.sernac.cl/portal/609/w3-propertyname-661.html, consulta: 20 de noviembre de 2018.

${ }^{50}$ En efecto, si se buscan las sentencias dictadas el año 2017 que responden a la palabra clave "daño moral", el buscador arroja un total de 64 sentencias, lo que es un número significativamente menor a las 390 sentencias analizadas en este trabajo, obtenidas de la manera detallada más adelante.

${ }^{51}$ Solicitudes de transparencia $\mathrm{N}^{\circ} \mathrm{AH} 009 \mathrm{~T} 001033$ y N${ }^{\circ} \mathrm{AH} 009 \mathrm{~T} 001034$, respectivamente, realizadas el 13 de abril de 2018, a través del Portal de Transparencia del SERNAC, en las que se solicitaron "copia de todas las sentencias definitivas ejecutoriadas el año 2017 (...) -tanto las que les fueron remitidas por los Juzgados de Policía Local en cumplimiento de lo dispuesto por el artículo 58 bis de la Ley $N^{\circ} 19.496$ como las obtenidas en la tramitación de juicios de interés general por vuestro Servicio- que fueron consideradas en el informe anual estadístico elaborado por vuestro Servicio el presente año, en virtud de lo dispuesto por el artículo $5^{\circ}$ del Reglamento del registro de sentencias de la Ley $N^{\circ} 19.496 "$ ".

${ }^{52}$ Oficio Ordinario N9497, dictado por la División Jurídica del SERNAC el 29 de mayo de 2018.

${ }_{53}$ Oficio Ordinario N ${ }^{\circ} 9496$, dictado por la División Jurídica del SERNAC el 29 de mayo de 2018.

${ }^{54}$ Cabe señalar que en el informe elaborado por la Subdirección Jurídica del SERNAC en marzo de 2018, acompañado por este Servicio como complemento de las respuestas a las solicitudes de información, se indica que el total de sentencias ejecutoriadas remitidas por los distintos JPL a nivel nacional durante el año 2017 es de 1.879 (SERVICIO NACIONAL DEL Consumidor, Estadística anual 2017. Registro Nacional de Sentencias Servicio Nacional del Consumidor, SERNAC, Santiago, 2018, p. 4. Se desconoce el motivo que explica esta brecha y sólo fue posible acceder a los fallos enumerados en los archivos entregados por el SERNAC.
} 
Con la información proporcionada en las tablas adjuntadas por el SERNAC, se revisó el Registro Público de Sentencias y se procedió a buscar y descargar cada uno de los fallos. ${ }^{55} \mathrm{~A}$ partir de esa búsqueda, se detectó que existen 28 sentencias que no se encuentran disponibles en dicho registro o que están incompletas de manera que no es posible comprender la decisión adoptada; ${ }^{56}$ y existen ocho sentencias referidas dos veces. En consecuencia, el total de sentencias disponibles y revisadas en este trabajo es de 842 . Asimismo, hay 341 sentencias respecto de las cuales, a pesar de lo señalado por el SERNAC, no consta su ejecutoriedad en el archivo descargado del Registro Público de Sentencias. ${ }^{57}$ Respecto a estas sentencias, se buscó la interposición de recursos de apelación en la sección "Consulta de causas" del Poder Judicial. De la misma manera, se indagó la posible interposición de recursos de queja ante la Corte Suprema respecto de todos los fallos que fueron conocidos por Cortes de Apelaciones en segunda instancia. En consecuencia, a pesar de que la ejecutoriedad de las sentencias analizadas no consta en todos los casos en el Registro Público de Sentencias, es posible entender que los fallos estudiados tienen este carácter.

\section{ANEXO 2}

Listado de sentencias definitivas, firmes y ejecutoriadas durante el año 2017, que conceden el daño moral demandado en causas de protección del interés individual de los consumidores ${ }^{58}$

\begin{tabular}{|c|c|c|c|c|c|c|c|}
\hline Región & $\begin{array}{l}\text { AÑo } \\
\text { INICIO }\end{array}$ & ROL & $\begin{array}{c}\text { JUZGADO POLICIA } \\
\text { LOCAL }\end{array}$ & $\begin{array}{l}\text { Rol recurso de } \\
\text { apelación }\end{array}$ & $\begin{array}{c}\text { Corte de } \\
\text { Apelaciones }\end{array}$ & Hecho infraccional & Cuantificación \\
\hline RM & 2016 & $11279-2016$ & JPL DE LA GRANJA & No apelada & $\mathrm{NA}$ & $\begin{array}{c}\text { Robo y daños al vehículo } \\
\text { en estacionamiento }\end{array}$ & $\$ 500.000$ \\
\hline RM & 2013 & $13824-2013$ & $3^{\circ} \mathrm{JPL}$ DE SANTIAGO & No apelada & $\mathrm{NA}$ & $\begin{array}{l}\text { Fraudes bancarios } 0 \\
\quad \text { financieros }\end{array}$ & $\$ 200.000$ \\
\hline
\end{tabular}

\footnotetext{
${ }^{55}$ Búsqueda efectuada durante el mes de junio de 2018.

${ }^{56}$ Se hace presente que no fueron contabilizadas como sentencias incompletas aquellas que, a pesar de no encontrarse íntegras en el Registro Público de Sentencias, son de todas maneras comprensibles. ${ }^{57}$ Para estos efectos, se comprendieron dentro de las sentencias ejecutoriadas, tanto aquellas que (i) cuentan con certificado de ejecutoriedad y/o (ii) resolución que ordena el cúmplase, como (iii) aquellas que fueron archivadas por el tribunal de primera instancia luego de la aprobación de un acuerdo conciliatorio, y (iv) aquellas que cuentan con una sentencia de segunda instancia.

${ }^{58}$ La Base de Datos completa se encuentra disponible en: Lazcano y Toro, cit. (n. 21).
} 


\begin{tabular}{|c|c|c|c|c|c|c|c|}
\hline Región & $\begin{array}{l}\text { AÑ0 } \\
\text { INICI0 }\end{array}$ & ROL & $\begin{array}{l}\text { JUZGAD0 POLICIA } \\
\text { LOCAL }\end{array}$ & $\begin{array}{l}\text { Rol recurso de } \\
\text { apelación }\end{array}$ & $\begin{array}{c}\text { Corte de } \\
\text { Apelaciones }\end{array}$ & Hecho infraccional & Cuantificación \\
\hline $\mathrm{RM}$ & 2016 & $7168-2016$ & JPL DE EL BOSQUE & No apelada & NA & Cobros injustificados & $\$ 300.000$ \\
\hline $\mathrm{RM}$ & 2016 & $35946-2016$ & JPL DE QUILICURA & No apelada & NA & $\begin{array}{l}\text { Producto defectuoso y/0 } \\
\text { incumplimiento garantía }\end{array}$ & $\$ 336.542$ \\
\hline $\mathrm{RM}$ & 2017 & $1975-2017$ & $\begin{array}{l}1^{\circ} \mathrm{JPL} \text { DE SAN } \\
\text { BERNARD0 }\end{array}$ & $1634-2017$ & San Miguel & $\begin{array}{c}\text { Robo y daños al vehículo } \\
\text { en estacionamiento }\end{array}$ & $\$ 300.000$ \\
\hline $\mathrm{RM}$ & 2016 & $3042-2016$ & $\begin{array}{l}1^{\circ} \text { JPL DE SAN } \\
\text { BERNARDO }\end{array}$ & $231-2016$ & San Miguel & $\begin{array}{l}\text { Robo y daños al vehículo } \\
\text { en estacionamiento }\end{array}$ & $\$ 300.000$ \\
\hline $\mathrm{RM}$ & 2016 & $7566-2016$ & $\begin{array}{l}2^{\circ} \text { JPL DE SAN } \\
\text { BERNARD0 }\end{array}$ & $162-2017$ & San Miguel & Cobros injustificados & $\$ 200.000$ \\
\hline $\mathrm{RM}$ & 2016 & $3461-2016$ & $\begin{array}{l}2^{\circ} \text { JPL DE SAN } \\
\text { BERNARD0 }\end{array}$ & $201-2017$ & San Miguel & $\begin{array}{l}\text { Interrupción / suspensión } \\
\text { injustificada de servicio }\end{array}$ & $\$ 200.000$ \\
\hline $\mathrm{RM}$ & 2016 & 25164-2016 & $\begin{array}{l}1^{\circ} \mathrm{JPL} \text { DE LAS } \\
\text { CONDES }\end{array}$ & No apelada & NA & $\begin{array}{l}\text { Incumplimiento de las } \\
\text { condiciones ofrecidas } \\
\text { y/o contratadas }\end{array}$ & $\$ 250.000$ \\
\hline $\mathrm{RM}$ & 2016 & $11904-2016$ & $\begin{array}{l}1^{\circ} \mathrm{JPL} \text { DE LAS } \\
\text { CONDES }\end{array}$ & $1551-2016$ & Santiago & $\begin{array}{c}\text { Falta de información } \\
\text { veraz y oportuna }\end{array}$ & $\$ 100.000$ \\
\hline $\mathrm{RM}$ & 2017 & $62926-2017$ & JPL DE CERRILLOS & No apelada & NA & $\begin{array}{c}\text { Robo / pérdida de } \\
\text { pertenencias dejadas en } \\
\text { custodia o lockers del } \\
\text { proveedor }\end{array}$ & $\$ 400.000$ \\
\hline $\mathrm{RM}$ & 2016 & $5228-2016$ & $\begin{array}{l}1^{\circ} \text { JPL DE SAN } \\
\text { BERNARD0 }\end{array}$ & $600-2017$ & San Miguel & $\begin{array}{l}\text { Producto defectuoso y/0 } \\
\text { incumplimiento garantía }\end{array}$ & $\$ 100.000$ \\
\hline $\mathrm{RM}$ & 2016 & $5448-2016$ & $3^{\circ}$ JPL DE MAIPÚ & $474-2017$ & Santiago & $\begin{array}{c}\text { Robo y daños al vehículo } \\
\text { en estacionamiento }\end{array}$ & $\$ 300.000$ \\
\hline $\mathrm{RM}$ & 2017 & $1045-2017$ & $1^{\circ} \mathrm{JPL}$ DE PUDAHUEL & No apelada & NA & $\begin{array}{l}\text { Pérdida / daño de } \\
\text { equipaje }\end{array}$ & $\$ 300.000$ \\
\hline $\mathrm{RM}$ & 2016 & $16788-2016$ & $1^{\circ} \mathrm{JPL}$ DE PUDAHUEL & No apelada & NA & $\begin{array}{l}\text { Pérdida / daño de } \\
\text { equipaje }\end{array}$ & $\$ 200.000$ \\
\hline $\mathrm{RM}$ & 2015 & $211-2015$ & JPL DE EL MONTE & No apelada & NA & $\begin{array}{l}\text { Incumplimiento de las } \\
\text { condiciones ofrecidas } \\
\text { y/o contratadas }\end{array}$ & $\$ 1.500 .000$ \\
\hline I & 2016 & $3512-2016$ & $1^{\circ} \mathrm{JPL}$ DE IQUIQUE & No apelada & NA & $\begin{array}{l}\text { Producto defectuoso y/0 } \\
\text { incumplimiento garantía }\end{array}$ & $\$ 300.000$ \\
\hline I & 2016 & $16229-2016$ & $2^{\circ} \mathrm{JPL}$ DE IQUIQUE & No apelada & NA & $\begin{array}{c}\text { Robo y daños al vehículo } \\
\text { en estacionamiento }\end{array}$ & $\$ 800.000$ \\
\hline I & 2015 & $11630-2015$ & $3^{\circ} \mathrm{JPL}$ DE IQUIQUE & $58-2016$ & Iquique & $\begin{array}{l}\text { Envío o mantención } \\
\text { injustificada en boletín } \\
\text { comercial }\end{array}$ & $\$ 2.000 .000$ \\
\hline I & 2016 & $12329-2016$ & $3^{\circ} \mathrm{JPL}$ DE IQUIQUE & $27-2017$ & Iquique & $\begin{array}{c}\text { Accidentes en las } \\
\text { dependencias del } \\
\text { proveedor }\end{array}$ & $\$ 6.000 .000$ \\
\hline
\end{tabular}




\begin{tabular}{|c|c|c|c|c|c|c|c|}
\hline Región & $\begin{array}{l}\text { AÑO } \\
\text { INICIO }\end{array}$ & ROL & $\begin{array}{c}\text { JUZGAD0 POLICIA } \\
\text { LOCAL }\end{array}$ & $\begin{array}{l}\text { Rol recurso de } \\
\text { apelación }\end{array}$ & $\begin{array}{c}\text { Corte de } \\
\text { Apelaciones }\end{array}$ & Hecho infraccional & Cuantificación \\
\hline II & 2016 & 20520-2016 & $\begin{array}{c}1^{\circ} \mathrm{JPL} \\
\text { ANTOFAGASTA }\end{array}$ & No apelada & NA & $\begin{array}{l}\text { Fraudes bancarios } 0 \\
\quad \text { financieros }\end{array}$ & $\$ 300.000$ \\
\hline II & 2015 & 22769-2015 & $\begin{array}{c}1^{\circ} \mathrm{JPL} \\
\text { ANTOFAGASTA }\end{array}$ & $83-2016$ & Antofagasta & $\begin{array}{l}\text { Fraudes bancarios } 0 \\
\text { financieros }\end{array}$ & $\$ 1.500 .000$ \\
\hline II & 2017 & 11683-2017 & $\begin{array}{c}1^{\circ} \mathrm{JPL} \\
\text { ANTOFAGASTA }\end{array}$ & No apelada & NA & $\begin{array}{l}\text { Fraudes bancarios } 0 \\
\quad \text { financieros }\end{array}$ & $\$ 300.000$ \\
\hline II & 2017 & 14416-2017 & $\begin{array}{c}1^{\circ} \mathrm{JPL} \\
\text { ANTOFAGASTA }\end{array}$ & $37-2017$ & Antofagasta & $\begin{array}{l}\text { Incumplimiento de las } \\
\text { condiciones ofrecidas } \\
\text { y/o contratadas }\end{array}$ & $\$ 2.000 .000$ \\
\hline II & 2016 & $17337-2016$ & $\begin{array}{c}1^{\circ} \mathrm{JPL} \\
\text { ANTOFAGASTA }\end{array}$ & No apelada & $\mathrm{NA}$ & $\begin{array}{l}\text { Fraudes bancarios } 0 \\
\text { financieros }\end{array}$ & $\$ 300.000$ \\
\hline II & 2017 & $1983-2017$ & $\begin{array}{c}1^{\circ} \mathrm{JPL} \\
\text { ANTOFAGASTA }\end{array}$ & No apelada & NA & $\begin{array}{c}\text { Negligencia en servicios } \\
\text { sanitarios que causa } \\
\text { daños }\end{array}$ & $\$ 2.000 .000$ \\
\hline II & 2016 & 21425-2016 & $\begin{array}{c}1^{\circ} \mathrm{JPL} \\
\text { ANTOFAGASTA }\end{array}$ & $111-2017$ & Antofagasta & $\begin{array}{l}\text { Pérdida / daño de } \\
\text { equipaje }\end{array}$ & $\$ 1.000 .000$ \\
\hline II & 2017 & 2184-2017 & $\begin{array}{c}1^{\circ} \mathrm{JPL} \\
\text { ANTOFAGASTA }\end{array}$ & $105-2017$ & Antofagasta & $\begin{array}{l}\text { Interrupción / suspensión } \\
\text { injustificada de servicio }\end{array}$ & $\$ 1.700 .000$ \\
\hline II & 2015 & $24377-2015$ & $\begin{array}{c}1^{\circ} \mathrm{JPL} \\
\text { ANTOFAGASTA }\end{array}$ & $29-2017$ & Antofagasta & $\begin{array}{l}\text { Pérdida / daño de } \\
\text { equipaje }\end{array}$ & $\$ 5.000 .000$ \\
\hline II & 2017 & $4687-2017$ & $\begin{array}{c}1^{\circ} \mathrm{JPL} \\
\text { ANTOFAGASTA }\end{array}$ & No apelada & $\mathrm{NA}$ & $\begin{array}{c}\text { Accidentes en las } \\
\text { dependencias del } \\
\text { proveedor }\end{array}$ & $\$ 2.000 .000$ \\
\hline II & 2017 & $5838-2017$ & $\begin{array}{c}1^{\circ} \mathrm{JPL} \\
\text { ANTOFAGASTA }\end{array}$ & $161-2017$ & Antofagasta & $\begin{array}{l}\text { Robo y daños al vehículo } \\
\text { en estacionamiento }\end{array}$ & $\$ 200.000$ \\
\hline II & 2017 & $5942-2017$ & $\begin{array}{c}1^{\circ} \mathrm{JPL} \\
\text { ANTOFAGASTA }\end{array}$ & $132-2017$ & Antofagasta & $\begin{array}{l}\text { Robo y daños al vehículo } \\
\text { en estacionamiento }\end{array}$ & $\$ 800.000$ \\
\hline II & 2017 & $6411-2017$ & $\begin{array}{c}1^{\circ} \mathrm{JPL} \\
\text { ANTOFAGASTA }\end{array}$ & No apelada & $\mathrm{NA}$ & $\begin{array}{l}\text { Producto defectuoso y/0 } \\
\text { incumplimiento garantía }\end{array}$ & $\$ 300.000$ \\
\hline II & 2017 & $7806-2017$ & $\begin{array}{c}1^{\circ} \mathrm{JPL} \\
\text { ANTOFAGASTA }\end{array}$ & No apelada & $\mathrm{NA}$ & $\begin{array}{l}\text { Retardo / no entrega de } \\
\text { una encomienda }\end{array}$ & $\$ 400.000$ \\
\hline II & 2015 & 25332-2015 & $1^{\circ} \mathrm{JPL}$ CALAMA & $158-2017$ & Antofagasta & $\begin{array}{c}\text { Envío o mantención } \\
\text { injustificada en boletín } \\
\text { comercial }\end{array}$ & $\$ 8.000 .000$ \\
\hline II & 2017 & 31419-2017 & $1^{\circ} \mathrm{JPL}$ CALAMA & $154-2017$ & Antofagasta & Otros & $\$ 150.000$ \\
\hline II & 2016 & $349-2016$ & $1^{\circ} \mathrm{JPL}$ TOCOPILLA & No apelada & $\mathrm{NA}$ & $\begin{array}{l}\text { Producto defectuoso y/0 } \\
\text { incumplimiento garantía }\end{array}$ & $\$ 88.000$ \\
\hline II & 2016 & $597-2016$ & $1^{\circ} \mathrm{JPL}$ TOCOPILLA & $127-2016$ & Antofagasta & $\begin{array}{l}\text { Pérdida / daño de } \\
\text { equipaje }\end{array}$ & $\$ 400.000$ \\
\hline II & 2015 & $756-2015$ & $1^{\circ} \mathrm{JPL}$ TOCOPILLA & No apelada & NA & $\begin{array}{l}\text { Retardo / no entrega de } \\
\text { una encomienda }\end{array}$ & $\$ 200.000$ \\
\hline
\end{tabular}




\begin{tabular}{|c|c|c|c|c|c|c|c|}
\hline Región & $\begin{array}{l}\text { AÑO } \\
\text { INICIO }\end{array}$ & ROL & $\begin{array}{c}\text { JUZGAD0 POLICIA } \\
\text { LOCAL }\end{array}$ & $\begin{array}{l}\text { Rol recurso de } \\
\text { apelación }\end{array}$ & $\begin{array}{c}\text { Corte de } \\
\text { Apelaciones }\end{array}$ & Hecho infraccional & Cuantificación \\
\hline II & 2015 & $2233-2015$ & $1^{\circ} \mathrm{JPL}$ TOCOPILLA & No apelada & $\mathrm{NA}$ & $\begin{array}{l}\text { Incumplimiento de las } \\
\text { condiciones ofrecidas } \\
\text { y/o contratadas }\end{array}$ & $\$ 170.000$ \\
\hline II & 2015 & $2779-2015$ & $1^{\circ} \mathrm{JPL}$ TOCOPILLA & No apelada & NA & $\begin{array}{l}\text { Interrupción / suspensión } \\
\text { injustificada de servicio }\end{array}$ & $\$ 100.000$ \\
\hline II & 2015 & $3033-2015$ & $1^{\circ} \mathrm{JPL}$ TOCOPILLA & $130-2016$ & Antofagasta & $\begin{array}{l}\text { Discriminación y trato } \\
\text { indigno en los sistemas } \\
\text { de seguridad y vigilancia }\end{array}$ & $\$ 200.000$ \\
\hline II & 2017 & $10672-2017$ & $\begin{array}{c}2^{\circ} \mathrm{JPL} \\
\text { ANTOFAGASTA }\end{array}$ & No apelada & NA & $\begin{array}{l}\text { Producto defectuoso y/0 } \\
\text { incumplimiento garantía }\end{array}$ & $\$ 200.000$ \\
\hline II & 2017 & $19002-2016$ & $\begin{array}{c}2^{\circ} \mathrm{JPL} \\
\text { ANTOFAGASTA }\end{array}$ & No apelada & $\mathrm{NA}$ & Cobros injustificados & $\$ 400.000$ \\
\hline II & 2017 & $19433-2016$ & $\begin{array}{c}2^{\circ} \mathrm{JPL} \\
\text { ANTOFAGASTA }\end{array}$ & $108-2017$ & Antofagasta & $\begin{array}{l}\text { Incumplimiento de las } \\
\text { condiciones ofrecidas } \\
\text { y/o contratadas }\end{array}$ & $\$ 100.000$ \\
\hline II & 2017 & $2398-2017$ & $\begin{array}{c}2^{\circ} \mathrm{JPL} \\
\text { ANTOFAGASTA }\end{array}$ & No apelada & NA & $\begin{array}{l}\text { Producto defectuoso y/0 } \\
\text { incumplimiento garantía }\end{array}$ & $\$ 200.000$ \\
\hline II & 2017 & $4312-2017$ & $\begin{array}{c}2^{\circ} \mathrm{JPL} \\
\text { ANTOFAGASTA }\end{array}$ & No apelada & NA & $\begin{array}{l}\text { Fraudes bancarios } 0 \\
\text { financieros }\end{array}$ & $\$ 500.000$ \\
\hline II & 2017 & $6627-2017$ & $\begin{array}{c}2^{\circ} \mathrm{JPL} \\
\text { ANTOFAGASTA }\end{array}$ & No apelada & $\mathrm{NA}$ & Servicio defectuoso & $\$ 300.000$ \\
\hline II & 2017 & $8202-2017$ & $\begin{array}{c}2^{\circ} \mathrm{JPL} \\
\text { ANTOFAGASTA }\end{array}$ & No apelada & NA & $\begin{array}{l}\text { Producto defectuoso y/0 } \\
\text { incumplimiento garantía }\end{array}$ & $\$ 200.000$ \\
\hline II & 2017 & $2947-2017$ & $\begin{array}{c}3^{\circ} \mathrm{JPL} \\
\text { ANTOFAGASTA }\end{array}$ & No apelada & NA & $\begin{array}{l}\text { Pérdida / daño de } \\
\text { equipaje }\end{array}$ & $\$ 1.500 .000$ \\
\hline III & 2015 & $6260-2015$ & $1^{\circ} \mathrm{JPL}$ DE COPIAPO & $6-2017$ & Copiapó & $\begin{array}{l}\text { Discriminación y trato } \\
\text { indigno en los sistemas } \\
\text { de seguridad y vigilancia }\end{array}$ & $\$ 200.000$ \\
\hline III & 2017 & $534-2017$ & $2^{\circ} \mathrm{JPL}$ DE COPIAPO & $41-2017$ & Copiapó & $\begin{array}{l}\text { Robo y daños al vehículo } \\
\text { en estacionamiento }\end{array}$ & $\$ 80.000$ \\
\hline III & 2017 & $1358-2017$ & $2^{\circ}$ JPL DE COPIAPO & No apelada & NA & Servicio defectuoso & $\$ 100.000$ \\
\hline III & 2016 & $5327-2016$ & 2 JPL DE COPIAPO & $10-2017$ & Copiapó & $\begin{array}{l}\text { Discriminación y trato } \\
\text { indigno en los sistemas } \\
\text { de seguridad y vigilancia }\end{array}$ & $\$ 700.000$ \\
\hline III & 2016 & $5574-2016$ & $2^{\circ} \mathrm{JPL}$ DE COPIAPO & $14-2017$ & Copiapó & $\begin{array}{c}\text { Incumplimiento de las } \\
\text { condiciones ofrecidas } \\
\text { y/o contratadas }\end{array}$ & $\$ 150.000$ \\
\hline III & 2017 & $4707-2017$ & JPL DE VALLENAR & No apelada & NA & $\begin{array}{c}\text { Negligencia en servicios } \\
\text { sanitarios que causa } \\
\text { daños }\end{array}$ & $\$ 2.500 .000$ \\
\hline
\end{tabular}




\begin{tabular}{|c|c|c|c|c|c|c|c|}
\hline Región & $\begin{array}{l}\text { AÑo } \\
\text { INICIO }\end{array}$ & ROL & $\begin{array}{l}\text { JUZGADO POLICIA } \\
\text { LOCAL }\end{array}$ & $\begin{array}{l}\text { Rol recurso de } \\
\text { apelación }\end{array}$ & $\begin{array}{c}\text { Corte de } \\
\text { Apelaciones }\end{array}$ & Hecho infraccional & Cuantificación \\
\hline III & 2016 & 9232-2016 & JPL DE VALLENAR & No apelada & NA & $\begin{array}{c}\text { Accidentes en las } \\
\text { dependencias del } \\
\text { proveedor }\end{array}$ & $\$ 5.000 .000$ \\
\hline IV & 2015 & 10095-2015 & $2^{\circ} \mathrm{JPL}$ LA SERENA & 248-2016 & La Serena & $\begin{array}{l}\text { Pérdida / daño de } \\
\text { equipaje }\end{array}$ & $\$ 1.000 .000$ \\
\hline IV & 2015 & $10097-2015$ & $2^{\circ} \mathrm{JPL}$ LA SERENA & 248-2016 & La Serena & $\begin{array}{l}\text { Pérdida / daño de } \\
\text { equipaje }\end{array}$ & $\$ 1.000 .000$ \\
\hline IV & 2014 & $5047-2014$ & $2^{\circ}$ JPL LA SERENA & 130-2016 & La Serena & Cobros injustificados & $\$ 500.000$ \\
\hline IV & 2016 & $8577-2016$ & JPL DE OVALLE & No apelada & NA & $\begin{array}{l}\text { Producto defectuoso y/o } \\
\text { incumplimiento garantía }\end{array}$ & $\$ 100.000$ \\
\hline IV & 2004 & 1780-2017 & JPL OVALLE & No apelada & NA & $\begin{array}{l}\text { Producto defectuoso y/o } \\
\text { incumplimiento garantía }\end{array}$ & $\$ 50.000$ \\
\hline IV & 2016 & 9983-2016 & JPL OVALLE & No apelada & $\mathrm{NA}$ & $\begin{array}{l}\text { Producto defectuoso } \mathrm{y} / 0 \\
\text { incumplimiento garantía }\end{array}$ & $\$ 300.000$ \\
\hline IX & 2013 & $\begin{array}{l}226835- \\
2013\end{array}$ & $1^{\circ}$ JPL DE TEMUCO & $15-2016$ & Temuco & $\begin{array}{c}\text { Incumplimiento de las } \\
\text { condiciones ofrecidas } \\
\text { y/o contratadas }\end{array}$ & $\$ 400.000$ \\
\hline IX & 2016 & $65418-2016$ & $2^{\circ} \mathrm{JPL}$ DE TEMUCO & No apelada & NA & $\begin{array}{l}\text { Producto defectuoso y/o } \\
\text { incumplimiento garantía }\end{array}$ & $\$ 150.000$ \\
\hline IX & 2016 & $67887-2016$ & $2^{\circ} \mathrm{JPL}$ DE TEMUCO & $87-2017$ & Temuco & $\begin{array}{c}\text { Envío o mantención } \\
\text { injustificada en boletín } \\
\text { comercial }\end{array}$ & $\$ 1.000 .000$ \\
\hline IX & 2016 & $68607-2016$ & $2^{\circ} \mathrm{JPL}$ DE TEMUCO & No apelada & NA & $\begin{array}{c}\text { Envío o mantención } \\
\text { injustificada en boletín } \\
\text { comercial }\end{array}$ & $\$ 5.000 .000$ \\
\hline IX & 2017 & 70207-2017 & $2^{\circ} \mathrm{JPL}$ DE TEMUCO & No apelada & NA & $\begin{array}{l}\text { Robo y daños al vehículo } \\
\text { en estacionamiento }\end{array}$ & $\$ 500.000$ \\
\hline IX & 2016 & 70890-2016 & $2^{\circ} \mathrm{JPL}$ DE TEMUCO & No apelada & NA & $\begin{array}{c}\text { Robo y daños al vehículo } \\
\text { en estacionamiento }\end{array}$ & $\$ 1.000 .000$ \\
\hline IX & 2016 & 71138-2016 & $2^{\circ} \mathrm{JPL}$ DE TEMUCO & 88-2017 & Temuco & $\begin{array}{c}\text { Robo y daños al vehículo } \\
\text { en estacionamiento }\end{array}$ & $\$ 1.000 .000$ \\
\hline IX & 2016 & 74541-2016 & $2^{\circ} \mathrm{JPL}$ DE TEMUCO & No apelada & NA & $\begin{array}{l}\text { Retardo en la entrega de } \\
\text { un producto comprado }\end{array}$ & $\$ 100.000$ \\
\hline IX & 2017 & 75742-2017 & $2^{\circ} \mathrm{JPL}$ DE TEMUCO & No apelada & NA & $\begin{array}{c}\text { Robo / pérdida de } \\
\text { pertenencias dejadas en } \\
\text { custodia o lockers del } \\
\text { proveedor }\end{array}$ & $\$ 100.000$ \\
\hline IX & 2017 & 77984-2017 & $2^{\circ} \mathrm{JPL}$ DE TEMUCO & No apelada & NA & $\begin{array}{c}\text { Robo y daños al vehículo } \\
\text { en estacionamiento }\end{array}$ & $\$ 300.000$ \\
\hline IX & 2017 & 79305-2017 & $2^{\circ} \mathrm{JPL}$ DE TEMUCO & No apelada & NA & $\begin{array}{l}\text { Discriminación y trato } \\
\text { indigno en los sistemas } \\
\text { de seguridad y vigilancia }\end{array}$ & $\$ 1.000 .000$ \\
\hline
\end{tabular}




\begin{tabular}{|c|c|c|c|c|c|c|c|}
\hline Región & $\begin{array}{l}\text { AÑO } \\
\text { INICIO }\end{array}$ & ROL & $\begin{array}{l}\text { JUZGAD0 POLICIA } \\
\text { LOCAL }\end{array}$ & $\begin{array}{l}\text { Rol recurso de } \\
\text { apelación }\end{array}$ & $\begin{array}{c}\text { Corte de } \\
\text { Apelaciones }\end{array}$ & Hecho infraccional & Cuantificación \\
\hline IX & 2017 & 82446-2017 & $2^{\circ} \mathrm{JPL}$ DE TEMUCO & No apelada & $\mathrm{NA}$ & $\begin{array}{l}\text { Retardo en la entrega de } \\
\text { un producto comprado }\end{array}$ & $\$ 300.000$ \\
\hline IX & 2012 & $\begin{array}{l}120214- \\
2012\end{array}$ & $3^{\circ} \mathrm{JPL}$ DE TEMUCO & No apelada & $\mathrm{NA}$ & Otros & $\$ 2.000 .000$ \\
\hline IX & 2015 & $\begin{array}{l}121.503- \\
2015\end{array}$ & $3^{\circ} \mathrm{JPL}$ DE TEMUCO & $71-2017$ & Temuco & $\begin{array}{l}\text { Discriminación y trato } \\
\text { indigno en los sistemas } \\
\text { de seguridad y vigilancia }\end{array}$ & $\$ 2.000 .000$ \\
\hline IX & 2016 & $\begin{array}{l}127977- \\
2016\end{array}$ & $3^{\circ} \mathrm{JPL}$ DE TEMUCO & No apelada & $\mathrm{NA}$ & $\begin{array}{c}\text { Robo y daños al vehículo } \\
\text { en estacionamiento }\end{array}$ & $\$ 150.000$ \\
\hline IX & 2016 & $\begin{array}{c}131029- \\
2016\end{array}$ & $3^{\circ} \mathrm{JPL}$ DE TEMUCO & No apelada & NA & $\begin{array}{l}\text { Producto defectuoso y/0 } \\
\text { incumplimiento garantía }\end{array}$ & $\$ 100.000$ \\
\hline V & 2016 & $1135-2016$ & JPL DE QUILLOTA & No apelada & NA & $\begin{array}{l}\text { Fraudes bancarios } 0 \\
\text { financieros }\end{array}$ & $\$ 250.000$ \\
\hline V & 2017 & $251-2017$ & JPL DE QUILLOTA & No apelada & NA & Cobros injustificados & $\$ 300.000$ \\
\hline $\mathrm{V}$ & 2017 & $289-2017$ & JPL DE QUILLOTA & No apelada & NA & Cobros injustificados & $\$ 300.000$ \\
\hline V & 2016 & $3339-2016$ & JPL DE QUILLOTA & No apelada & NA & $\begin{array}{l}\text { Producto defectuoso y/0 } \\
\text { incumplimiento garantía }\end{array}$ & $\$ 100.000$ \\
\hline $\mathrm{V}$ & 2016 & $3669-2016$ & JPL DE QUILLOTA & No apelada & $\mathrm{NA}$ & $\begin{array}{l}\text { Producto defectuoso y/0 } \\
\text { incumplimiento garantía }\end{array}$ & $\$ 30.000$ \\
\hline VI & 2015 & $\begin{array}{l}490097- \\
2015\end{array}$ & $1^{\circ} \mathrm{JPL}$ RANCAGUA & $140-2016$ & Rancagua & $\begin{array}{l}\text { Producto defectuoso y/0 } \\
\text { incumplimiento garantía }\end{array}$ & $\$ 1.000 .000$ \\
\hline VII & 2017 & $283-2017$ & $1^{\circ} \mathrm{JPL}$ DE CURICO & No apelada & NA & $\begin{array}{l}\text { Producto defectuoso y/0 } \\
\text { incumplimiento garantía }\end{array}$ & $\$ 40.000$ \\
\hline VII & 2016 & $6696-2016$ & $1^{\circ} \mathrm{JPL}$ TALCA & No apelada & NA & $\begin{array}{l}\text { Producto defectuoso y/0 } \\
\text { incumplimiento garantía }\end{array}$ & $\$ 150.000$ \\
\hline VII & 2015 & $1026-2015$ & $1^{\circ} \mathrm{JPL}$ TALCA & No apelada & NA & Cobros injustificados & $\$ 100.000$ \\
\hline VII & 2016 & $572-2016$ & $1^{\circ} \mathrm{JPL}$ TALCA & No apelada & NA & $\begin{array}{c}\text { Robo y daños al vehículo } \\
\text { en estacionamiento }\end{array}$ & $\$ 2.000 .000$ \\
\hline VII & 2011 & $5909-2011$ & $1^{\circ} \mathrm{JPL}$ TALCA & No apelada & NA & $\begin{array}{c}\text { Robo y daños al vehículo } \\
\text { en estacionamiento }\end{array}$ & $\$ 2.000 .000$ \\
\hline VII & 2010 & $6370-2010$ & $1^{\circ} \mathrm{JPL}$ TALCA & $2836-2016$ & Talca & Cobros injustificados & $\$ 600.000$ \\
\hline VII & 2015 & $8457-2015$ & $1^{\circ} \mathrm{JPL}$ TALCA & No apelada & NA & $\begin{array}{l}\text { Producto defectuoso y/0 } \\
\text { incumplimiento garantía }\end{array}$ & $\$ 300.000$ \\
\hline VII & 2011 & $8649-2011$ & $1^{\circ} \mathrm{JPL}$ TALCA & No apelada & NA & $\begin{array}{c}\text { Envío o mantención } \\
\text { injustificada en boletín } \\
\text { comercial }\end{array}$ & $\$ 1.300 .000$ \\
\hline VII & 2015 & $3888-2015$ & $2^{\circ} \mathrm{JPL}$ DE CURICO & No apelada & NA & $\begin{array}{c}\text { Robo y daños al vehículo } \\
\text { en estacionamiento }\end{array}$ & $\$ 500.000$ \\
\hline VII & 2016 & $1477-2016$ & $2^{\circ} \mathrm{JPL}$ TALCA & $1020-2017$ & Talca & $\begin{array}{l}\text { Fraudes bancarios } 0 \\
\text { financieros }\end{array}$ & $\$ 500.000$ \\
\hline
\end{tabular}




\begin{tabular}{|c|c|c|c|c|c|c|c|}
\hline Región & $\begin{array}{l}\text { AÑo } \\
\text { INICIO }\end{array}$ & ROL & $\begin{array}{l}\text { JUZGADO POLICIA } \\
\text { LOCAL }\end{array}$ & $\begin{array}{l}\text { Rol recurso de } \\
\text { apelación }\end{array}$ & $\begin{array}{c}\text { Corte de } \\
\text { Apelaciones }\end{array}$ & Hecho infraccional & Cuantificación \\
\hline VII & 2016 & $4090-2016$ & $2^{\circ} \mathrm{JPL}$ TALCA & No apelada & NA & $\begin{array}{l}\text { Robo y daños al vehículo } \\
\text { en estacionamiento }\end{array}$ & $\$ 50.000$ \\
\hline VII & 2017 & $175-2017$ & $3^{\circ} \mathrm{JPL}$ TALCA & No apelada & NA & $\begin{array}{l}\text { Producto defectuoso y/o } \\
\text { incumplimiento garantía }\end{array}$ & $\$ 50.000$ \\
\hline VII & 2007 & $3080-2015$ & $3^{\circ} \mathrm{JPL}$ TALCA & $575-2016$ & Talca & $\begin{array}{l}\text { Producto defectuoso y/o } \\
\text { incumplimiento garantía }\end{array}$ & $\$ 700.000$ \\
\hline VII & 2016 & $3949-2016$ & $3^{\circ} \mathrm{JPL}$ TALCA & $136-2017$ & Talca & $\begin{array}{l}\text { Producto defectuoso y/o } \\
\text { incumplimiento garantía }\end{array}$ & $\$ 2.000 .000$ \\
\hline VIII & 2017 & $3251-2017$ & $1^{\circ} \mathrm{JPL}$ CHILLAN & No apelada & NA & $\begin{array}{l}\text { Producto defectuoso y/o } \\
\text { incumplimiento garantía }\end{array}$ & $\$ 200.000$ \\
\hline VIII & 2017 & $72-2017$ & $1^{\circ} \mathrm{JPL}$ CHILLAN & No apelada & NA & $\begin{array}{l}\text { Incumplimiento de las } \\
\text { condiciones ofrecidas } \\
\text { y/o contratadas }\end{array}$ & $\$ 60.000$ \\
\hline VIII & 2010 & $21627-2010$ & $1^{\circ} \mathrm{JPL}$ CONCEPCION & No apelada & $\mathrm{NA}$ & Cobros injustificados & $\$ 600.000$ \\
\hline IX & 2016 & $\begin{array}{l}234646- \\
2016\end{array}$ & $1^{\circ}$ JPL DE TEMUCO & $69-2017$ & Temuco & $\begin{array}{l}\text { Producto defectuoso y/o } \\
\text { incumplimiento garantía }\end{array}$ & $\$ 250.000$ \\
\hline VIII & 2014 & $4391-2014$ & $2^{\circ} \mathrm{JPL}$ CHILLAN & $66-2016$ & Chillán & $\begin{array}{l}\text { Producto defectuoso y/o } \\
\text { incumplimiento garantía }\end{array}$ & $\$ 500.000$ \\
\hline VIII & 2015 & $2144-2015$ & $2^{\circ} \mathrm{JPL}$ CONCEPCION & No apelada & NA & $\begin{array}{l}\text { Robo y daños al vehículo } \\
\text { en estacionamiento }\end{array}$ & $\$ 1.500 .000$ \\
\hline VIII & 2015 & $7604-2015$ & 2 JPL CHILLÁN & $27-2017$ & Chillán & Cobros injustificados & $\$ 500.000$ \\
\hline VIII & 2015 & $5804-2015$ & $3^{\circ}$ JPL CONCEPCION & No apelada & NA & $\begin{array}{l}\text { Robo y daños al vehículo } \\
\text { en estacionamiento }\end{array}$ & $\$ 300.000$ \\
\hline X & 2016 & $5407-2016$ & $\begin{array}{l}1^{\circ} \text { JPL DE PUERTO } \\
\text { MONTT }\end{array}$ & No apelada & NA & Otros & $\$ 5.000 .000$ \\
\hline$X$ & 2017 & $1130-2017$ & $1^{\circ}$ JPL OSORNO & No apelada & NA & $\begin{array}{l}\text { Producto defectuoso y/o } \\
\text { incumplimiento garantía }\end{array}$ & $\$ 200.000$ \\
\hline X & 2016 & $5278-2016$ & $2^{\circ} \mathrm{JPL}$ DE OSORNO & 73-2017 & Valdivia & $\begin{array}{l}\text { Producto defectuoso y/o } \\
\text { incumplimiento garantía }\end{array}$ & $\$ 300.000$ \\
\hline$X$ & 2016 & $7539-2016$ & $2^{\circ} \mathrm{JPL}$ DE OSORNO & No apelada & NA & $\begin{array}{l}\text { Robo y daños al vehículo } \\
\text { en estacionamiento }\end{array}$ & $\$ 500.000$ \\
\hline $\mathrm{X}$ & 2016 & 1171-2016 & $2^{\circ} \mathrm{JPL}$ DE OSORNO & 91-2017 & Valdivia & Otros & $\$ 500.000$ \\
\hline X & 2016 & $3222-2016$ & $2^{\circ} \mathrm{JPL}$ DE OSORNO & 22-2017 & Valdivia & $\begin{array}{c}\text { Incumplimiento de } \\
\text { obligación de alzamiento } \\
\text { de hipoteca dentro de } \\
\text { plazo }\end{array}$ & $\$ 1.000 .000$ \\
\hline $\mathrm{X}$ & 2015 & $5750-2015$ & $2^{\circ} \mathrm{JPL}$ DE OSORNO & 243-2016 & Valdivia & Cobros injustificados & $\$ 100.000$ \\
\hline X & 2015 & $8309-2015$ & $2^{\circ}$ JPL DE OSORNO & $374-2016$ & Valdivia & $\begin{array}{l}\text { Producto defectuoso y/o } \\
\text { incumplimiento garantía }\end{array}$ & $\$ 200.000$ \\
\hline X & 2015 & $8947-2015$ & $2^{\circ} \mathrm{JPL}$ DE OSORNO & No apelada & NA & $\begin{array}{l}\text { Retardo / no entrega de } \\
\text { una encomienda }\end{array}$ & $\$ 300.000$ \\
\hline
\end{tabular}




\begin{tabular}{|c|c|c|c|c|c|c|c|}
\hline Región & $\begin{array}{l}\text { AÑO } \\
\text { INICIO }\end{array}$ & ROL & $\begin{array}{c}\text { JUZGAD0 POLICIA } \\
\text { LOCAL }\end{array}$ & $\begin{array}{l}\text { Rol recurso de } \\
\text { apelación }\end{array}$ & $\begin{array}{c}\text { Corte de } \\
\text { Apelaciones }\end{array}$ & Hecho infraccional & Cuantificación \\
\hline $\mathrm{X}$ & 2015 & $3532-2015$ & $\begin{array}{c}2^{\circ} \mathrm{JPL} \text { DE PUERTO } \\
\text { MONTT }\end{array}$ & $153-2016$ & Puerto Montt & $\begin{array}{l}\text { Robo y daños al vehículo } \\
\text { en estacionamiento }\end{array}$ & $\$ 200.000$ \\
\hline$X$ & 2015 & $2774-2015$ & $\begin{array}{c}3^{\circ} \mathrm{JPL} \text { DE PUERTO } \\
\text { MONTT }\end{array}$ & No apelada & $\mathrm{NA}$ & $\begin{array}{l}\text { Producto defectuoso y/0 } \\
\text { incumplimiento garantía }\end{array}$ & $\$ 2.000 .000$ \\
\hline$X$ & 2015 & $6434-2015$ & $\begin{array}{c}3^{\circ} \text { JPL DE PUERTO } \\
\text { MONTT }\end{array}$ & No apelada & $\mathrm{NA}$ & $\begin{array}{l}\text { Interrupción / suspensión } \\
\text { injustificada de servicio }\end{array}$ & $\$ 5.000 .000$ \\
\hline$X$ & 2016 & $390-2016$ & $\begin{array}{c}3^{\circ} \text { JPL DE PUERTO } \\
\text { MONTT }\end{array}$ & No apelada & $\mathrm{NA}$ & $\begin{array}{l}\text { Pérdida / daño de } \\
\text { equipaje }\end{array}$ & $\$ 500.000$ \\
\hline $\mathrm{X}$ & 2016 & $392-2016$ & $\begin{array}{c}3^{\circ} \mathrm{JPL} \text { DE PUERTO } \\
\text { MONTT }\end{array}$ & $4-2017$ & Puerto Montt & $\begin{array}{c}\text { Robo y daños al vehículo } \\
\text { en estacionamiento }\end{array}$ & $\$ 1.000 .000$ \\
\hline$X$ & 2015 & $15-2015$ & JPL CASTRO & No apelada & NA & Cobros injustificados & $\$ 300.000$ \\
\hline$X$ & 2013 & $60012-2013$ & JPL CASTRO & No apelada & NA & $\begin{array}{l}\text { Discriminación y trato } \\
\text { indigno en los sistemas } \\
\text { de seguridad y vigilancia }\end{array}$ & $\$ 2.500 .000$ \\
\hline$X$ & 2016 & $1292-2016$ & JPL PUERTO VARAS & No apelada & NA & Otros & $\$ 600.000$ \\
\hline XIV & 2016 & $3883-2016$ & $1^{\circ} \mathrm{JPL}$ VALDIVIA & 226-2017 & Valdivia & $\begin{array}{c}\text { Accidentes en las } \\
\text { dependencias del } \\
\text { proveedor }\end{array}$ & $\$ 1.000 .000$ \\
\hline XIV & 2017 & $3435-2017$ & $2^{\circ} \mathrm{JPL}$ VALDIVIA & $254-2017$ & Valdivia & $\begin{array}{l}\text { Retardo / no entrega de } \\
\text { una encomienda }\end{array}$ & $\$ 300.000$ \\
\hline XIV & 2017 & $3557-2017$ & $2^{\circ} \mathrm{JPL}$ VALDIVIA & $227-2017$ & Valdivia & $\begin{array}{l}\text { Envío o mantención } \\
\text { injustificada en boletín } \\
\text { comercial }\end{array}$ & $\$ 200.000$ \\
\hline XIV & 2016 & $6417-2016$ & $2^{\circ} \mathrm{JPL}$ VALDIVIA & No apelada & NA & $\begin{array}{c}\text { Robo y daños al vehículo } \\
\text { en estacionamiento }\end{array}$ & $\$ 200.000$ \\
\hline $\mathrm{XV}$ & 2017 & $1105-2017$ & $1^{\circ} \mathrm{JPL}$ DE ARICA & $12-2018$ & Arica & Otros & $\$ 500.000$ \\
\hline XV & 2017 & $764-2017$ & $2^{\circ} \mathrm{JPL}$ DE ARICA. & No apelada & NA & $\begin{array}{c}\text { Incumplimiento de las } \\
\text { condiciones ofrecidas } \\
\text { y/o contratadas }\end{array}$ & $\$ 300.000$ \\
\hline XV & 2017 & $778-2017$ & $2^{\circ} \mathrm{JPL}$ DE ARICA. & No apelada & NA & $\begin{array}{c}\text { Incumplimiento de las } \\
\text { condiciones ofrecidas } \\
\text { y/o contratadas }\end{array}$ & $\$ 500.000$ \\
\hline$X V$ & 2017 & $779-2017$ & $2^{\circ} \mathrm{JPL}$ DE ARICA. & No apelada & NA & $\begin{array}{c}\text { Incumplimiento de las } \\
\text { condiciones ofrecidas } \\
\text { y/o contratadas }\end{array}$ & $\$ 500.000$ \\
\hline XV & 2016 & $10312-2016$ & $3^{\circ} \mathrm{JPL}$ DE ARICA & No apelada & NA & $\begin{array}{c}\text { Incumplimiento de } \\
\text { obligación de alzamiento } \\
\text { de hipoteca dentro de } \\
\text { plazo }\end{array}$ & $\$ 100.000$ \\
\hline XV & 2017 & $111-2017$ & $3^{\circ} \mathrm{JPL}$ DE ARICA & No apelada & NA & $\begin{array}{l}\text { Retardo en la entrega de } \\
\text { un producto comprado }\end{array}$ & $\$ 200.000$ \\
\hline
\end{tabular}




\begin{tabular}{|c|c|c|c|c|c|c|c|}
\hline Región & $\begin{array}{l}\text { AÑO } \\
\text { INICI0 }\end{array}$ & ROL & $\begin{array}{l}\text { JUZGADO POLICIA } \\
\text { LOCAL }\end{array}$ & $\begin{array}{l}\text { Rol recurso de } \\
\text { apelación }\end{array}$ & $\begin{array}{c}\text { Corte de } \\
\text { Apelaciones }\end{array}$ & Hecho infraccional & Cuantificación \\
\hline XV & 2017 & $162-2017$ & $3^{\circ} \mathrm{JPL}$ DE ARICA & No apelada & NA & $\begin{array}{l}\text { Fraudes bancarios } 0 \\
\quad \text { financieros }\end{array}$ & $\$ 500.000$ \\
\hline XV & 2017 & $352-2017$ & $3^{\circ} \mathrm{JPL}$ DE ARICA & No apelada & NA & $\begin{array}{l}\text { Incumplimiento de las } \\
\text { condiciones ofrecidas } \\
\text { y/o contratadas }\end{array}$ & $\$ 1.500 .000$ \\
\hline $\mathrm{XV}$ & 2017 & $384-2017$ & $3^{\circ} \mathrm{JPL}$ DE ARICA & No apelada & NA & $\begin{array}{l}\text { Retardo / no entrega de } \\
\text { una encomienda }\end{array}$ & $\$ 500.000$ \\
\hline XV & 2017 & $476-2017$ & $3^{\circ} \mathrm{JPL}$ DE ARICA & No apelada & $\mathrm{NA}$ & $\begin{array}{l}\text { Incumplimiento de las } \\
\text { condiciones ofrecidas } \\
\text { y/o contratadas }\end{array}$ & $\$ 500.000$ \\
\hline $\mathrm{XV}$ & 2017 & $477-2017$ & $3^{\circ} \mathrm{JPL}$ DE ARICA & No apelada & NA & $\begin{array}{c}\text { Pérdida / daño de } \\
\text { equipaje }\end{array}$ & $\$ 50.000$ \\
\hline $\mathrm{XV}$ & 2017 & $894-2017$ & $3^{\circ} \mathrm{JPL}$ DE ARICA & No apelada & NA & $\begin{array}{l}\text { Incumplimiento de las } \\
\text { condiciones ofrecidas } \\
\text { y/o contratadas }\end{array}$ & $\$ 100.000$ \\
\hline $\mathrm{XV}$ & 2016 & $962-2016$ & $3^{\circ} \mathrm{JPL}$ DE ARICA & $19-2017$ & Arica & $\begin{array}{l}\text { Incumplimiento de las } \\
\text { condiciones ofrecidas } \\
\text { y/o contratadas }\end{array}$ & $\$ 1.000 .000$ \\
\hline
\end{tabular}

